This item was submitted to Loughborough's Research Repository by the author.

Items in Figshare are protected by copyright, with all rights reserved, unless otherwise indicated.

\title{
Non-linear vibro-impact phenomenon belying transmission idle rattle
}

PLEASE CITE THE PUBLISHED VERSION

PUBLISHER

Professional Engineering Publishing / @ IMECHE

VERSION

VoR (Version of Record)

LICENCE

CC BY-NC-ND 4.0

REPOSITORY RECORD

Tangasawi, Osman A.M., Stephanos Theodossiades, Homer Rahnejat, and P. Kelly. 2019. "Non-linear Vibroimpact Phenomenon Belying Transmission Idle Rattle”. figshare. https://hdl.handle.net/2134/4700. 
This item was submitted to Loughborough's Institutional Repository (https://dspace.lboro.ac.uk/) by the author and is made available under the following Creative Commons Licence conditions.

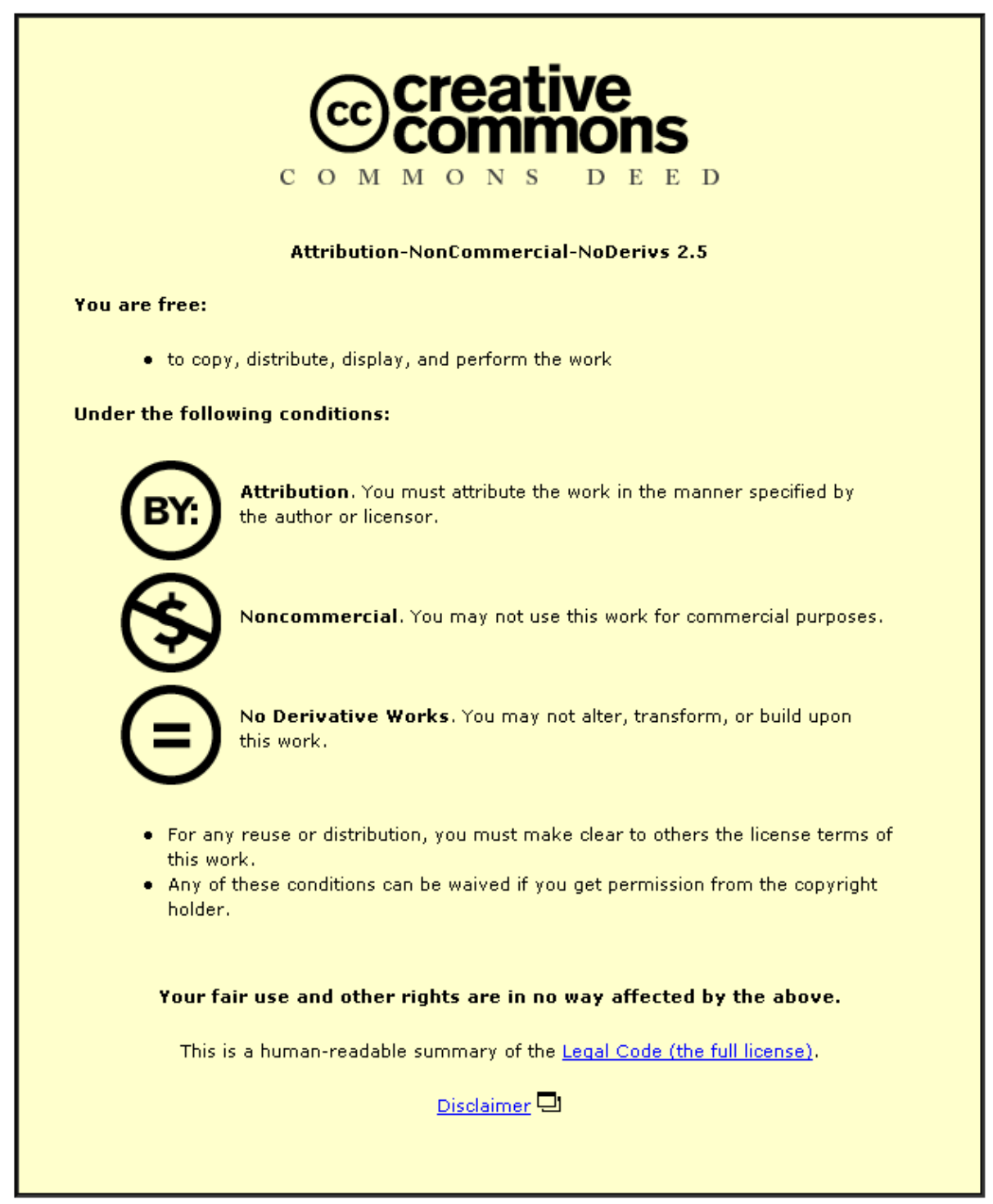

For the full text of this licence, please go to: http://creativecommons.org/licenses/by-nc-nd/2.5/ 


\title{
Non-linear vibro-impact phenomenon belying transmission idle rattle
}

\author{
O Tangasawi $^{1}$, S Theodossiades $^{1 *}$, H Rahnejat $^{1}$, and P Kelly ${ }^{2}$ \\ ${ }^{1}$ Wolfson School of Mechanical and Manufacturing Engineering, University of Loughborough, Loughborough, UK \\ ${ }^{2}$ Powertrain Engineering, Ford Werke AG, Merkenich, Cologne, Germany
}

The manuscript was received on 25 October 2007 and was accepted after revision for publication on 3 June 2008.

DOI: 10.1243/09544062JMES922

\begin{abstract}
This paper investigates automotive transmission gear rattle. Specifically, idle gear rattle, where the repetitive impacts of teeth are subject to light loads is investigated. Hydrodynamic regime of lubrication prevails in lightly loaded impact of teeth pairs. Formation of a lubricant film is due to the combined entraining motion of the lubricant and squeeze film effect. A lumped parameter inertial dynamic model, comprising hydrodynamic impact and flank friction for pairs of simultaneous teeth pairs of loose gears is developed. The overall dynamic model includes seven loose gear pairs and rigid body lateral motions of input and output transmission shafts. Therefore, the influence of fluid film behaviour on idle gear rattle is determined, which has hitherto not attracted sufficient research studies.

Gear rattle is manifested by a vibration signature, which corresponds to the bands of frequencies due to torsional engine oscillations, meshing frequencies, and impact characteristics of lubricated conjunctions. The spectral contributions are affected by lubricant rheology, specifically its bulk viscosity variation with temperature. It has been found that spectral disposition tends towards lower frequency contributions with reducing lubricant viscosity because of rising temperatures and lowering lubricant stiffness. The findings conform with the experimental results, also reported in the paper. It has also been shown that squeeze film motion plays a significant role in the propensity of transmission system to rattle.
\end{abstract}

Keywords: transmission rattle, engine idling condition, lightly loaded hydrodynamic impact

\section{INTRODUCTION}

The internal combustion engine produces a fluctuating torque due to the combustion, as well as the induced inertial imbalance of the reciprocating pistons. When the clutch is engaged, the resulting torsional oscillations of the crankshaft are transmitted to the gearbox. In the transmission, the fixed driving gears (pinions) transfer the motion to the driven unselected (idle) gears through impacting teeth pairs in close proximity. This is because of the compact nature of modern transmission systems. The driven gears in turn rotate freely on their bearing surfaces

\footnotetext{
${ }^{*}$ Corresponding author: Wolfson School of Mechanical and Manufacturing Engineering, University of Loughborough, Loughborough LE11 3TU,UK.email: s.theodossiades@lboro.ac.uk
}

with their retaining shafts, as they are unselected. They are referred to as loose gears. As a result, the idle gears oscillate within their backlash limits, leading to impacts with the driving gears. Vibrations caused by these impacts are transmitted through the gearbox shafts and their support bearings to the transmission bell housing, which then radiates sound, which resembles the noise produced when a marble rolls inside a metallic can. This sound is onomatopoeically referred to as rattle. Idle (neutral) rattle occurs when the engine runs at its idling speed. The transmission is set to neutral (no gear is selected) and the clutch is engaged [1]. This condition produces the highest rattle intensity compared with other forms of gear rattle, as the engine noise level is at its minimum [2]. Furthermore, under idling condition the vehicle is usually stationary, for example at a traffic light or situated near other stationary vehicles, thus the radiated noise 
from the transmission is reflected from neighbouring surfaces. This accentuates the noise perception by the vehicle occupants and other road users. Kim and Singh [3] pointed out that the rattle favours loose (idle) gears, because they are unconstrained, thus move freely when teeth pair separation occurs. The condition for separation to occur is when the inertial torque of the idle gear is larger than the applied load (i.e. the resisting torque) [4].

Gear contacts have been modelled usually as deadspace functions with a constant teeth-pair contact stiffness [3-7]. Other contact models have included time-varying piecewise linear stiffness functions [2], or have used the classical Hertzian theory [8] or other time-varying functions $[\mathbf{9}, \mathbf{1 0}]$. In the aforementioned models, damping has been mainly included as drag torque between the loose gear and its retaining shaft in the system $[\mathbf{3}, \mathbf{5}, \mathbf{1 1}, \mathbf{1 2}]$ with constant coefficients or those proportional to the penetration velocity (mutual convergence of gear teeth flanks) [7-9]. The effect of lubricant film squeeze action has been considered by Brancati et al. [10] and Gnanakumarr et al. [13]. Brancati et al. [10] assumed non-linear damping due to a squeeze film adsorbed on the teeth. On the other hand, in reference [13], no metal-to-metal contact was considered. Instead, a hydrodynamic lubricant reaction was assumed to be present at all times between the approaching and rolling convergent wedge of teeth pairs. The latter approach is valid for low loads transmitted by unselected gears, where the contact stiffness is governed by the lowest stiffness, which is that due to a hydrodynamic film, rather than that due to a Hertzian contact, requiring localized deformation. The latter is unlikely at light loads under idle rattle condition.

Experimental studies by Sakai et al. [5] showed that rattle occurs when the inertial torque of an idle gear exceeds its drag torque. Therefore, when the ratio, $\mathrm{RR}=$ inertia torque/drag torque, exceeds unity, rattle is thought to occur. This ratio is called the rattle ratio. Seaman et al. [11] defined the rattle threshold as the angular acceleration at which the inertial torque at the unloaded teeth mesh exceeds the drag torque at the same mesh. A similar approach was also undertaken by Smith [14].

Engine speed fluctuations have been found to be an important factor, affecting gear vibrations and emitted noise levels. The larger the fluctuations, the higher the rattle response becomes according to Sakai et al. [5]. Gear backlash has a similar effect when doublesided impacts take place between pinion and gear teeth pairs $[5,11,15]$. Furthermore, when the centre distance of a gear pair is decreased, the noise level is also decreased [15].

It has been found that drag torque is higher at lower temperatures $[\mathbf{5}, \mathbf{1 1}, \mathbf{1 6}]$ and, therefore, rattle noise is somewhat attenuated. It is, therefore, surmised that lubricant viscosity plays an important role as the film thickness reduces and thus viscous friction increases. It introduces a drag torque between the gear and the shaft, which dampens the impacts between the gear teeth, thus attenuating the radiated noise. Seaman et al. [11] showed that at the same oil sump temperature, drag torque is higher at faster rotational speeds, but as temperature increases, the variation between different values of drag torque at different rotational speeds decreases. Therefore, theoretically, there should be a temperature at which the drag torque is the same for all rotational speeds. However, Fujimoto and Kizuka [17] reported that there is an optimum temperature range, at which rattle is at its minimum.

This paper presents numerical models for a gear pair contact, as well as for a complete transmission system in order to investigate idle rattle conditions. The method is validated through comparisons with experimental measurements taken from a vehicle under the same conditions. Parametric studies are also presented for both the aforementioned models in order to explain experimental observations reported by various researchers and shed some light on the physical behaviour of a rattling system.

\section{THEORETICAL FORMULATION}

The single-degree-of-freedom model for a gear pair comprises a driving gear (pinion) and an idling driven gear (Fig. 1) mounted on a retaining shaft via a conformal bearing surface. The angular displacement $\varphi_{p}(t)$, velocity $\dot{\varphi}_{\mathrm{p}}(t)$, and acceleration $\ddot{\varphi}_{\mathrm{p}}(t)$ time histories of the pinion are known kinematic quantities for a given engine running condition (Fig. 2 shows the

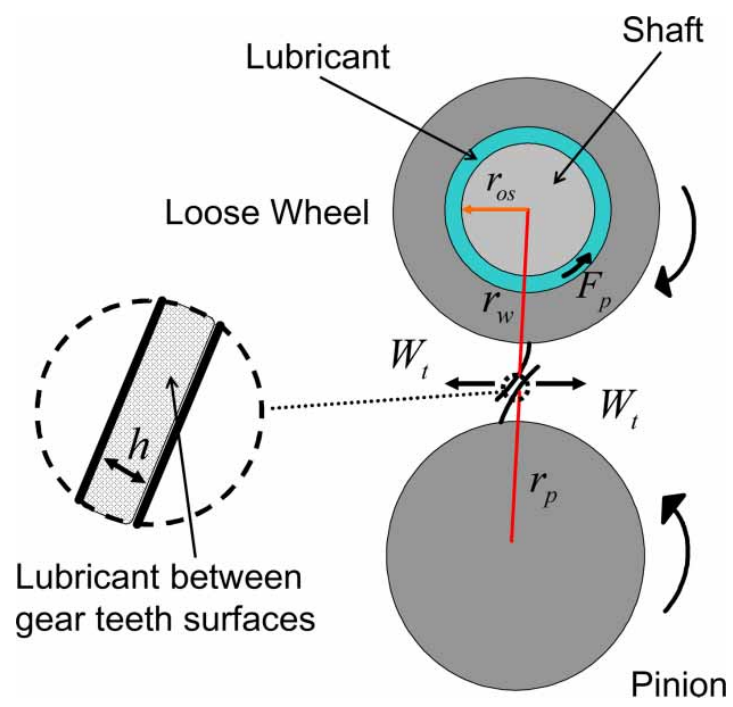

Fig. 1 The gear pair model 

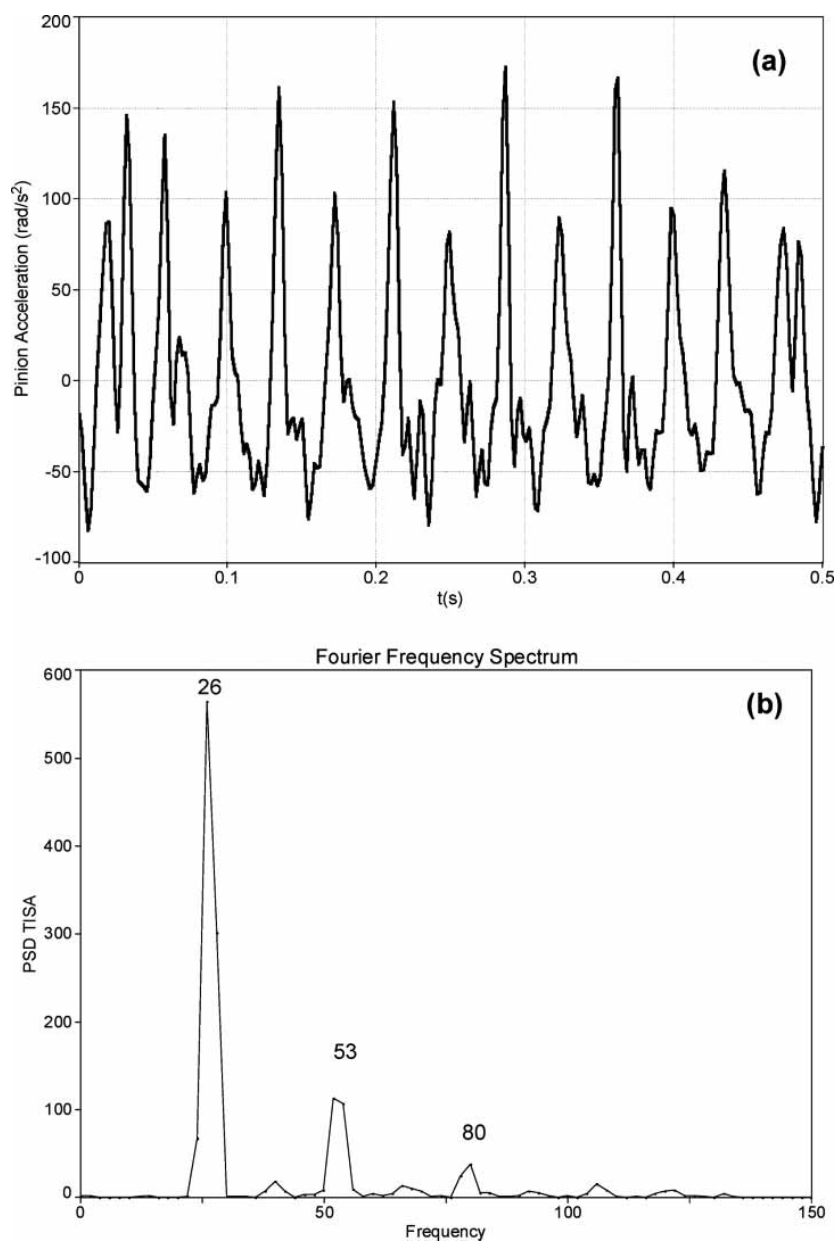

Fig. 2 Pinion's acceleration (a) time history and (b) frequency spectrum

pinion's acceleration in time and frequency domains). The equation of motion of the loose gear wheel is obtained as

$$
I_{\mathrm{w}} \ddot{\varphi}_{\mathrm{w}}=\sum^{N}\left(W \cos \beta_{\mathrm{b}} r_{\mathrm{bw}}\right)-\sum^{N}\left(F_{\mathrm{f}} \rho_{\mathrm{w}}\right)-F_{\mathrm{p}} r_{\mathrm{s}}
$$

The wheel is driven by a hydrodynamic (contact) force, $W$, applied by the normally approaching and rolling pinion teeth. The motion is resisted by the hydrodynamic friction force, $F_{\mathrm{f}}$, acting on the teeth flanks, and a tractive force, $F_{\mathrm{p}}$, due to the action of the lubricant between the loose wheel and its supporting shaft. The hydrodynamic reaction force is calculated for line contact condition as [18]

$$
\left.\begin{array}{ll}
W_{j}=\frac{L_{j} \eta_{0} r_{\mathrm{eq} j}}{h}\left(2 u_{j}-\frac{3 \pi}{\sqrt{2 h / r_{\mathrm{eq} j}}} \frac{\partial h}{\partial t}\right), & \text { if } \frac{\partial h}{\partial t}<0 \\
W_{j}=\frac{L_{j} \eta_{0} r_{\mathrm{eq} j}}{h}\left(2 u_{j}\right), & \text { if } \quad \frac{\partial h}{\partial t} \geqslant 0
\end{array}\right\}
$$

The rigid film thickness (rigid hydrodynamic contact) is given by

$$
h=C_{\mathrm{b}}-\frac{\left|\left(r_{\mathrm{bw}} \varphi_{\mathrm{w}}-r_{\mathrm{bp}} \varphi_{\mathrm{p}}\right)\right|}{\cos \alpha_{\mathrm{n}} \cos \beta}
$$

The viscous friction force acting on the tooth flank surface as a result of the lubricant film shearing is given by Gohar [19] as

$$
F_{\mathrm{fj}}=\frac{\pi \eta_{0} L_{j}\left|u_{\mathrm{s} j}\right| \sqrt{r_{\mathrm{eq} j}}}{\sqrt{2 h}}
$$

The tractive force between the gear wheel and the supporting shaft is known as Petrov friction in a conforming hydrodynamic contact as

$$
F_{\mathrm{p}}=\frac{\pi \eta_{0} \nu l_{1} r_{\mathrm{s}}}{C}
$$

More details on equations (1) to (5) are provided in references [20] and [21].

The seven-speed (including reverse) transaxle transmission was modelled using known angular displacement $\varphi_{\text {in }}(t)$, velocity $\dot{\varphi}_{\text {in }}(t)$, and acceleration $\ddot{\varphi}_{\text {in }}(t)$ time histories of the transmission input shaft from experimental measurements in a vehicle (Fig. 2). The seven torsional degrees of freedom representing the idle gears are shown in Fig. 3. Each gear $i(i=1, \ldots, 7)$ is driven by the hydrodynamic reaction force, $W_{i}$, due to its contact with its pinion. Each idle gear is also subjected to a hydrodynamic friction force, $F_{\mathrm{fi}}$, along its meshing teeth flanks and the tractive force, $F_{\mathrm{pi}}$, due to the lubricant action between the loose gear wheel and its retaining shaft. The motion of the first gear, however, is also resisted by the hydrodynamic reaction force due to the contact between the reverse pinion and its idling gear, $W_{7}$. Therefore, the equation of motion for the first speed idling gear is obtained as

$$
\begin{aligned}
I_{1} \ddot{\varphi}_{1}= & \sum_{N_{1}}^{N_{1}}\left(W_{1} \cos \beta_{\mathrm{b} 1} r_{\mathrm{b} 1}\right)-\sum^{N_{7}}\left(W_{7} \cos \beta_{\mathrm{b} 7} r_{\mathrm{bp} 7}\right) \\
& -\sum^{N_{1}}\left(F_{\mathrm{f} 1} \rho_{1}\right)-F_{\mathrm{p} 1} r_{\mathrm{s} 1}
\end{aligned}
$$

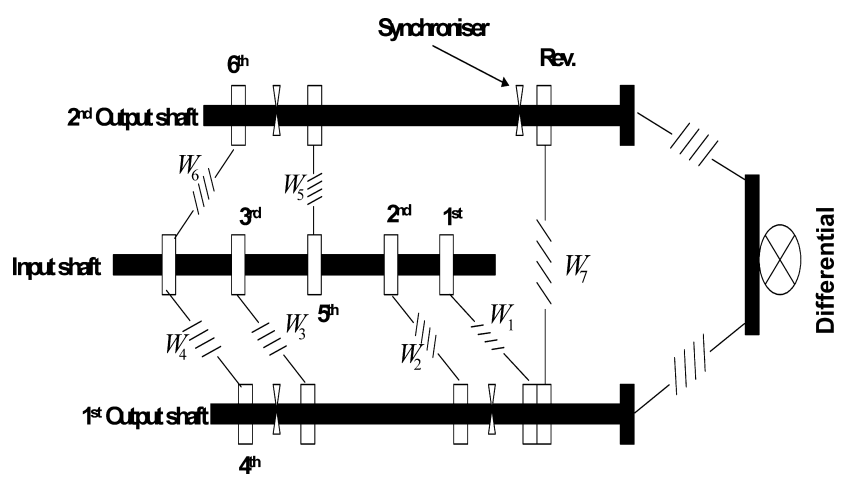

Fig. 3 The idle gear pairs of the manual transmission 
The remaining idle gear wheels $(i=2, \ldots, 7)$ are represented by the following equation

$$
I_{1} \ddot{\varphi}_{1}=\sum^{N_{1}}\left(W_{i} \cos \beta_{\mathrm{b} i} r_{\mathrm{b} i}\right)-\sum^{N_{i}}\left(F_{\mathrm{f} i} \rho_{i}\right)-F_{\mathrm{p} i} r_{\mathrm{s} i}
$$

The radii $r_{\mathrm{bi}=1, \ldots, 7}$ are the base radii of the idle gears and $r_{\mathrm{bp} 7}$ is the base radius of the reverse pinion, whereas $r_{s i=1, \ldots, 7}$ are the internal radii of the idle gears, which represent the outside radii of the conforming bearings (between loose gears and their retaining shafts). The hydrodynamic reaction force $W_{i}$ and the teeth friction force $F_{\mathrm{f} i}(i=1,2, \ldots, 7)$ are, respectively, the hydrodynamic and friction forces acting on each tooth pair in simultaneous contact. The transverse degrees of freedom of the supporting shafts are determined along two arbitrary orthogonal coordinates for each shaft. The equations of motion for the two shafts are obtained as follows:

For the first shaft (Fig. 4, views A and C) in the $x_{1}$ and $y_{1}$ directions, respectively

$$
M_{1} \ddot{x}_{1}=F_{x 1}-\Lambda_{\mathrm{a} x}-\Lambda_{\mathrm{b} x}
$$
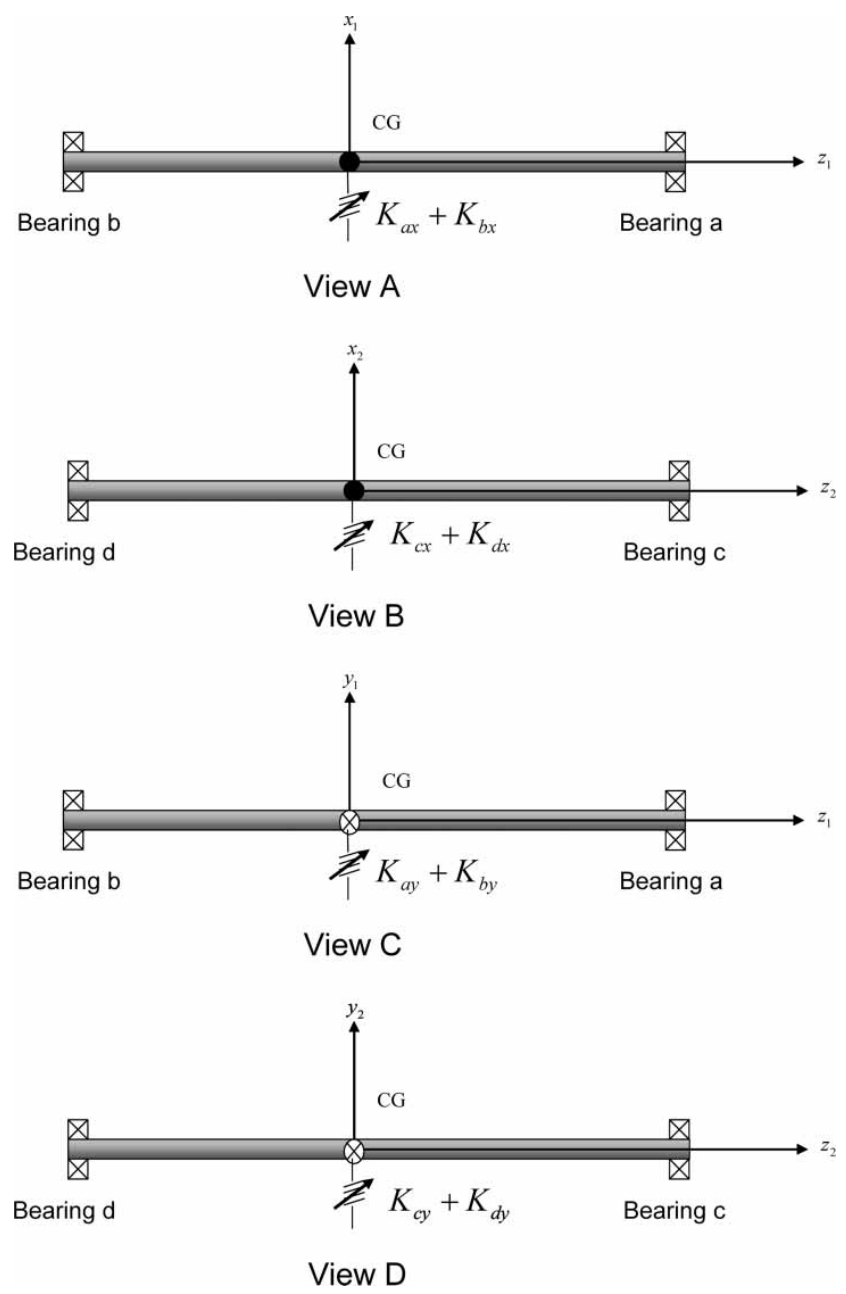

Fig. 4 The lateral degrees of freedom of the seven-speed manual transmission

$$
M_{1} \ddot{y}_{1}=F_{y 1}-\Lambda_{\mathrm{a} y}-\Lambda_{\mathrm{b} y}
$$

And for the second shaft (Fig. 4, views B and D) in the $x_{2}$ and $y_{2}$ directions, respectively

$$
\begin{aligned}
& M_{2} \ddot{x}_{2}=F_{x 2}-\Lambda_{\mathrm{c} x}-\Lambda_{\mathrm{d} x} \\
& M_{2} \ddot{y}_{2}=F_{y 2}-\Lambda_{\mathrm{c} y}-\Lambda_{\mathrm{d} y}
\end{aligned}
$$

Forces $F_{x 1}, F_{y 1}, F_{x 2}$, and $F_{y 2}$ are the resultants acting on the shafts due to the respective components of the hydrodynamic film reactions taken in the $x_{1}, y_{1}, x_{2}$, and $y_{2}$ directions. These forces couple the transverse degrees of freedom with the torsional degrees of freedom. The forces denoted by $\Lambda_{\mathrm{ax}}, \Lambda_{\mathrm{a} y}, \Lambda_{\mathrm{b} x}, \Lambda_{\mathrm{b} y}, \Lambda_{\mathrm{c} x}, \Lambda_{\mathrm{c} y}, \Lambda_{\mathrm{d} x}$, and $\Lambda_{\mathrm{d} y}$ are the support bearing reactions. They are calculated, based on the stiffness coefficients: $K_{\mathrm{a} x}, K_{\mathrm{ay}}, K_{\mathrm{b} x}, K_{\mathrm{b} y}, K_{\mathrm{c} x}, K_{\mathrm{c} y}, K_{\mathrm{d} x}$, and $K_{\mathrm{d} y}$ as shown in Fig. 4. The supporting tapered roller bearings behave as non-linear springs in the $x_{1}, y_{1}, x_{2}$, and $y_{2}$ directions. Assuming no radial clearance, the total restoring force $\Lambda_{k r}$ of the $k$ th bearing acting in the $x$ - or $y$-direction can be calculated according to Harris [22] as

$$
\begin{aligned}
\Lambda_{k r}= & 0.2453 m_{k} Q_{k r} \delta_{k r}^{1.11} \cos \gamma_{k} \\
& \left(k=a, b, c, d ; r=x_{1}, y_{1}, x_{2}, y_{2}\right)
\end{aligned}
$$

$Q_{k r}$ is the reduced coefficient of the inner and outer raceways' contacts with a taper roller and is determined as follows

$$
Q_{k r}=\frac{7.86 \times 10^{4} l_{k}^{8 / 9}}{2^{1.11}}
$$

Combining the above equations yields the following expression for the radial restoring force $\Lambda_{k r}$

$$
\Lambda_{k r}=\frac{l_{k}^{8 / 9} m_{k} \cos \gamma_{k}}{1.12 \times 10^{-4}} \delta_{k r}^{1.11}=K_{k} \delta_{k r}^{1.11}
$$

where $\gamma_{k}$ is the contact angle, $l_{k}$ is the roller length, and $m_{k}$ is the number of rollers per row of the $k$ th bearing. The radial deformation (pseudo-penetration), $\delta_{k r}$, can be estimated using a suitably small time step from the instantaneous displacement, $d_{k}$, of the shaft at the relevant bearing support as

$$
\delta_{k r}= \begin{cases}d_{k}-\Delta_{k}, & d_{k}>\Delta_{k} \\ 0, & -\Delta_{k} \leqslant d_{k} \leqslant \Delta_{k} \\ d_{k}+\Delta_{k}, & d_{k}<-\Delta_{k}\end{cases}
$$

where $\Delta_{k}$ is the radial clearance of bearing $k$ and the displacement $d_{k}$ is equal to $x_{1 a}, y_{1 a}, x_{1 b}, y_{1 b}, x_{2 c}, y_{2 c}, x_{2 d}$, or $y_{2 d}$, which correspond to $x$ and $y$ displacements at bearings $a, b, c$, and $d$, respectively. As the infinitesimal 
rocking motions of the shafts are ignored, it can be concluded that

$$
\left.\begin{array}{l}
x_{1 \mathrm{a}}=x_{1 \mathrm{~b}}=x_{1} \\
y_{1 \mathrm{a}}=y_{1 \mathrm{~b}}=y_{1} \\
x_{2 \mathrm{c}}=x_{2 \mathrm{~d}}=x_{2} \\
y_{2 \mathrm{c}}=y_{2 \mathrm{~d}}=y_{2}
\end{array}\right\}
$$

Hence, with any clearance, the radial reaction force is a piecewise non-linear function and can be expressed as

$$
\Lambda_{k r}= \begin{cases}-\operatorname{sign}\left(d_{k}\right) K_{k}\left|\delta_{k r}\right|^{1.11}, & d_{k}>\Delta_{k}, d_{k}<-\Delta_{k} \\ 0, & \left|d_{k}\right| \leqslant \Delta_{k}\end{cases}
$$

The main assumptions of the method are as follows.

1. During engine idling condition, light teeth-pair impact loads and sufficient loose gear speeds permit the formation of a hydrodynamic lubricant film between the mating teeth-pairs.

2. Due to the low-impact forces (of the order of a few Newtons), shaft bending $(0.1-0.3 \mu \mathrm{m})$ has been neglected. These are in fact one and two orders of magnitude lower than the bearing deformations. Shaft elasticity effects are more important when high loads are transmitted to the drivetrain.

3 . The rocking motion of the shafts are not included as this would significantly complicate the calculation of lubricant film thickness between the teeth flanks, an assumption that is justified because of the light impact loads during idling conditions. Furthermore, the aim of this work is to focus on the effect of lubricant film behaviour.

4. The gear tooth profile is considered to follow a perfect involute.

5. No misalignments are considered.

6. No tooth-to-tooth geometrical variations exist.

7. The loads on the teeth are too low to cause any local or global deformation of the teeth (local being due to Hertzian condition and global being due to tooth bending or rocking).

8. Changes of viscosity due to generated pressures within the contact zone are considered as negligible because of low hydrodynamic pressures (i.e. iso-viscous assumption).

9. No other forms of external excitations other than engine torsional excitations are considered.

The equations of motion are solved in a series of suitably small time steps using Newmark's linear acceleration method $[\mathbf{1 8}, \mathbf{2 3}]$. The parameters of the Newmark integration scheme were carefully selected so as to minimize numerical damping and improve its accuracy albeit at the expense of conditional stability $[\mathbf{2 3}, \mathbf{2 4}]$. To cater for the problem of numerical stability, care had to be taken in the selection of a suitable time step size ( $1 \mu \mathrm{s})$ and definition of initial conditions. Sufficiently, long simulation run times were undertaken in order to exceed well beyond any initial transience.

\section{EXPERIMENTAL SET-UP}

Vehicle tests were carried out in a semi-anechoic chamber under engine idling condition (with the transmission in the neutral position). Tests were carried out at various oil sump temperatures. Piezoelectric accelerometers were used to capture vibrations of the gearbox housing, following the response path from the bearing housings to the transmission wall. A total of five accelerometers were used in the vehicle measurements. The three accelerometers, whose results are analysed in this paper, were arranged as follows.

1. Two accelerometers were mounted on the transmission housing wall at the locations of shafts' bearing supports; the input shaft (indicated by (1) in Fig. 5) and the second (upper) output shaft (indicated by (2) in Fig. 5).

2. An accelerometer was mounted on the under-side of the transmission bell housing (indicated by (3) in Fig. 5), where the wall is relatively compliant (away from the bell housing ribs).

Additionally, a thermocouple was inserted into the oil-filling hole, measuring the transmission oil spray temperature. The data acquisition sampling rate was set to $12000 \mathrm{~Hz}$; hence, giving a Nyquist frequency of $6000 \mathrm{~Hz}$, which is more than sufficient for gear rattle measurements.

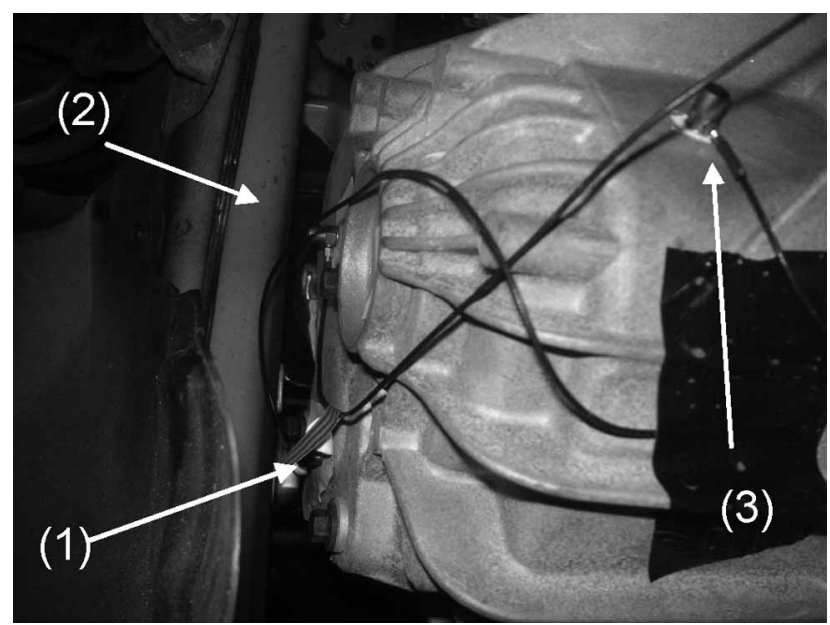

Fig. 5 Accelerometers mounted on the gearbox surface 


\section{PARAMETRIC STUDIES - DISCUSSION}

Parametric studies were conducted for a gear pair model and also for the full seven-speed transmission model. The former was used as a simple model to demonstrate the basic gear vibration phenomena, before proceeding to a more complex full transmission model. The latter is used to examine the interactions between the torsional and lateral degrees of freedom, as well as for comparison purposes and validation against the experimental measurements.

\subsection{The gear pair model}

The gear pair in the first set of aforementioned parametric studies has the geometric properties of the fifth gear pair of the manual transmission used in the experimental measurements. The clearance between the loose gear and its retaining shaft is $35 \mu \mathrm{m}$, whereas the backlash value for teeth-pairs is $79 \mu \mathrm{m}$. Figures 6 and 7
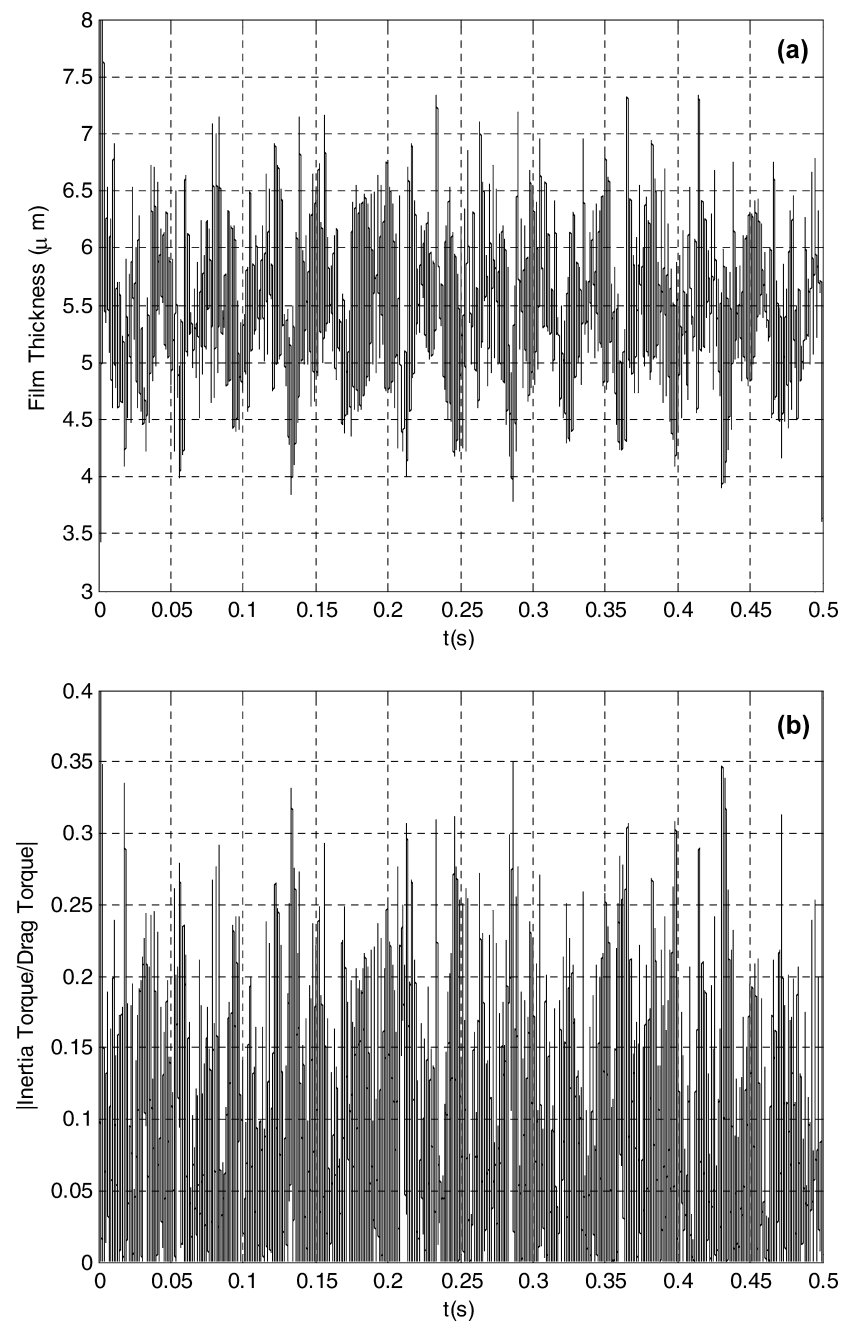

Fig. 6 (a) Film thickness and (b) rattle ratio time histories at $20^{\circ} \mathrm{C}$
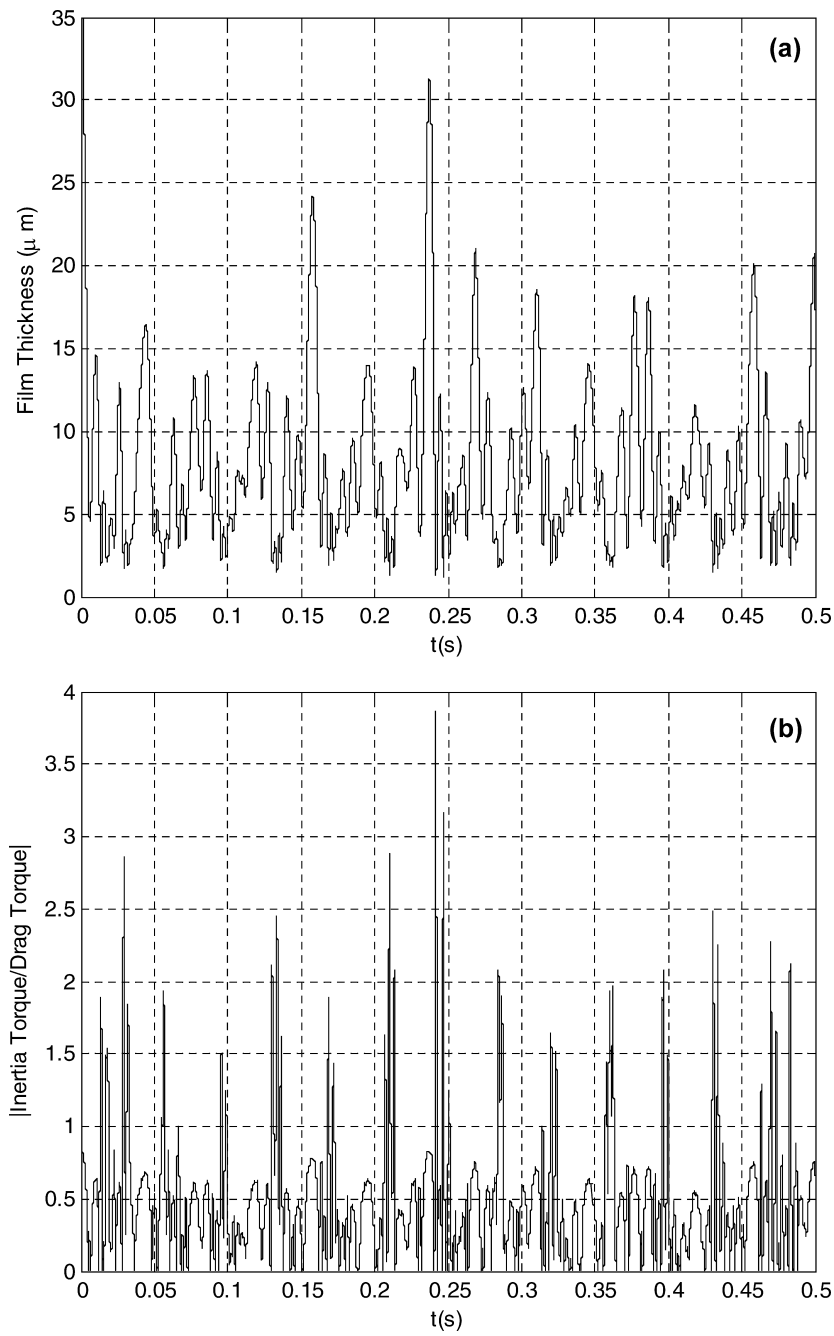

Fig. 7 (a) Film thickness and (b) rattle ratio time histories at $80^{\circ} \mathrm{C}$

show that as the lubricant viscosity drops due to rising temperature, the rattle ratio increases and crosses the threshold $(\mathrm{RR}=1)$ at $80^{\circ} \mathrm{C}$ (see Fig. $7(\mathrm{a})$ : where the separation between the meshing teeth markedly increases). This can be seen in the corresponding variations in the oil film thickness (Figs 6 and 7). Reduced lubricant viscosity at higher temperatures decreases the Petrov friction for a given assumed clearance. This results in reduced drag torque, thus an increased rattle ratio. A by-product of this is increased teeth separations, hence increased impact force and inertial torque. These figures show greater separations with increased temperature or reduced lubricant viscosity (from $\approx 3 \mu \mathrm{m}$ peak-to-peak variation at $20^{\circ} \mathrm{C}$ to more than $10 \mu \mathrm{m}$ at $80^{\circ} \mathrm{C}$ ).

Figure 8 shows that the threshold for the onset of rattle is mainly breached by the wheel, when the pinion motion undergoes a rise in acceleration. Furthermore, pinion acceleration shows that the peaks tend to be stronger at a spacing of $13 \mathrm{~Hz}$ (first-engine 


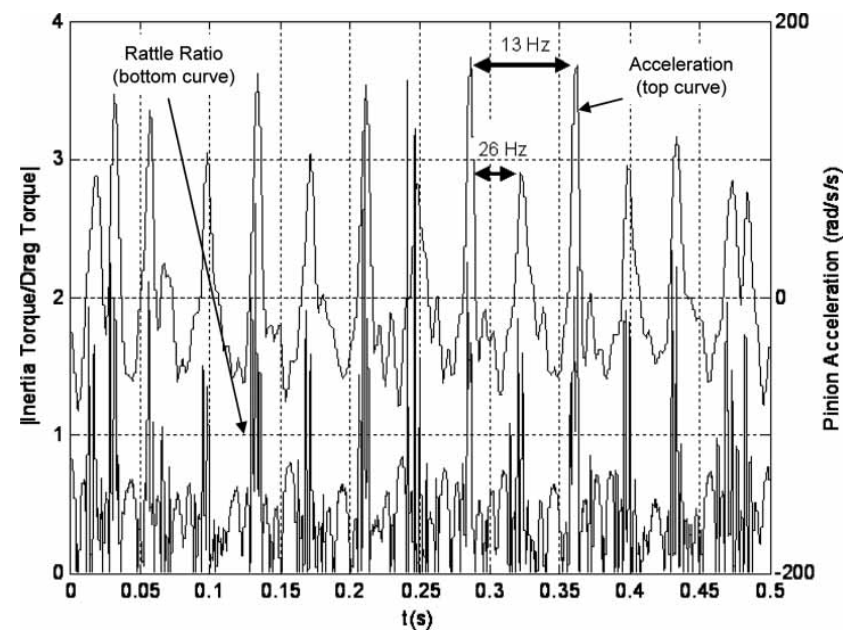

Fig. 8 Rattle ratio (lower curve/left label) and pinion acceleration (upper curve/right label) time histories at $80^{\circ} \mathrm{C}$

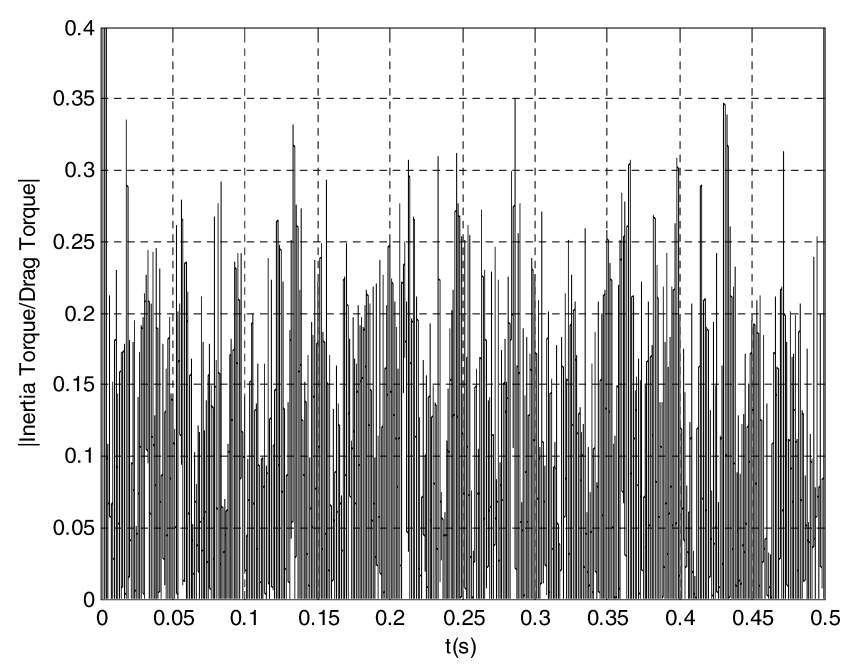

Fig. 9 Rattle ratio at $20^{\circ} \mathrm{C}$ and $158 \mu \mathrm{m}$ backlash

order) rather than the expected second-engine order. The effect of backlash for one-sided impacts (Fig. 9) shows little influence on the rattle ratio when comparing with Fig. 6(a). This is in line with the findings of Sakai et al. [5], Seaman et al. [4], Rust et al. [1], and Doğan [15].

The dominant influential parameter in idle rattle is the lubricant viscosity variation with temperature. Lower viscosity shifts the response frequencies to a lower spectral region, as well as lowering the amplitude of oscillations at the higher spectral contributions (Fig. 10). The spectral contributions comprise engine order excitations (approximately at 26, 52, 78, and $106 \mathrm{~Hz})$, the gear meshing frequency $(465 \mathrm{~Hz})$, and a band of frequencies related to contact stiffness. As the bulk oil temperature increases this band of frequencies shifts towards the lower spectral region (Figs 10(b) and (c)). Modulation is observed in the
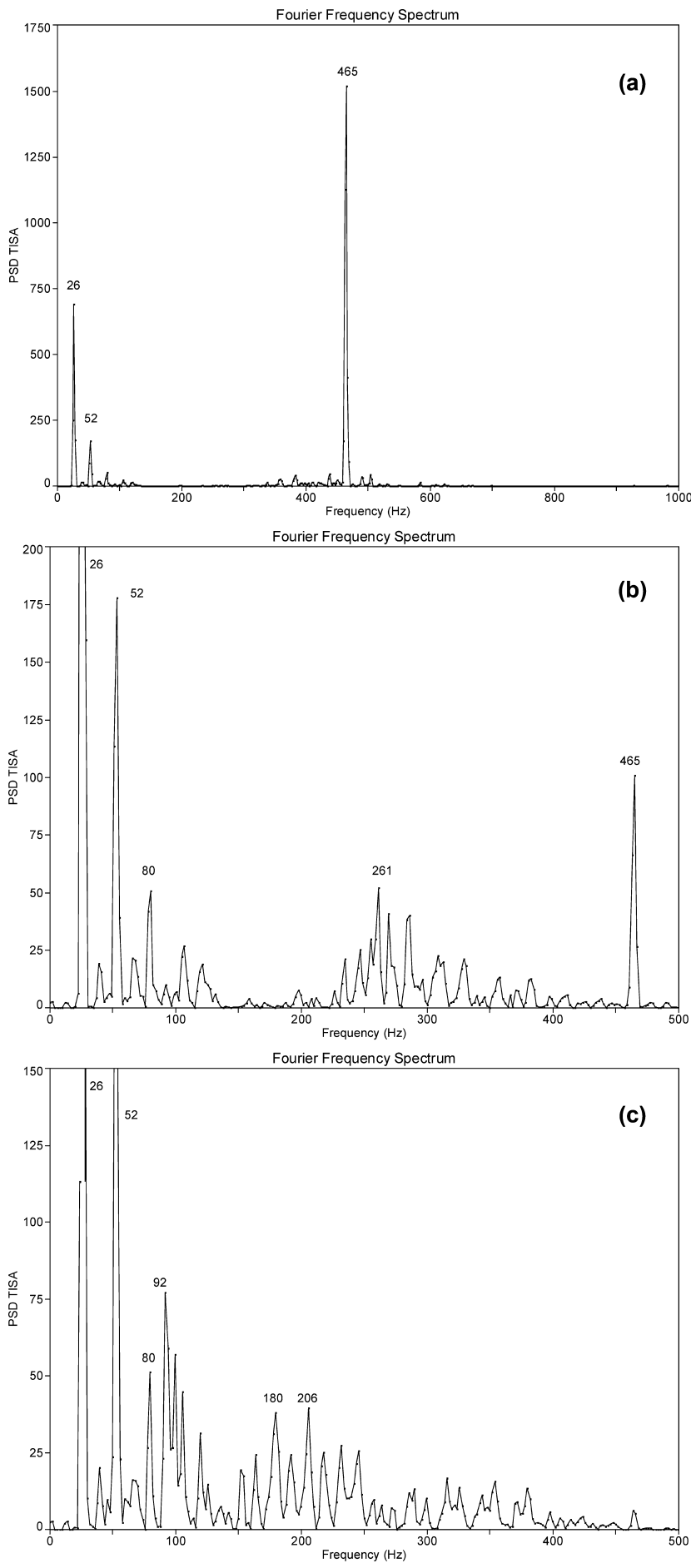

Fig. 10 FFT spectra of the gear wheel response at (a) $20^{\circ} \mathrm{C}$, (b) $39.4{ }^{\circ} \mathrm{C}$, and (c) $80^{\circ} \mathrm{C}$

spectra at the pinion rotational frequency of $13 \mathrm{~Hz}$. At $20^{\circ} \mathrm{C}$ (Fig. $10(\mathrm{a})$ ), the gear meshing frequency is dominant. As the temperature rises to $39.4^{\circ} \mathrm{C}$ (Fig. $10(\mathrm{~b}))$, the engine orders become dominant, and the frequency due to lubricated impacts makes its appearance $(261 \mathrm{~Hz})$. At a lower temperature, the drag torque dominates (higher system effective torsional stiffness). 
Therefore, the spectrum of vibration is dominated by the meshing frequency, similar to a pair of load transmitting gears. With decreasing drag torque due to reduced Petrov friction, the impact energy is dissipated by vibrations within lubricated contacts and damping of engine torsional vibration is less effective. Finally, in Fig. 10 (c) $\left(80^{\circ} \mathrm{C}\right)$, the band of impact-related frequencies shifts further to lower spectral region due to a further reduction in the hydrodynamic stiffness. The moving band of frequencies can be associated with gear rattling by correlating the change in rattle ratio with lowered viscosity, reduced Petrov friction, and larger contact separations (the trend is shown in Figs 6 and 7).

With a $79 \mu \mathrm{m}$ backlash at $20^{\circ} \mathrm{C}$, the frequency response shifts to the lower spectral region as the clearance between the gear and the retaining shaft increases (Fig. 11). This is because the thicker hydrodynamic films have lower stiffness and viscous friction. With much reduced clearance, Fig. 11(a) shows vibration at high frequency with a greater share
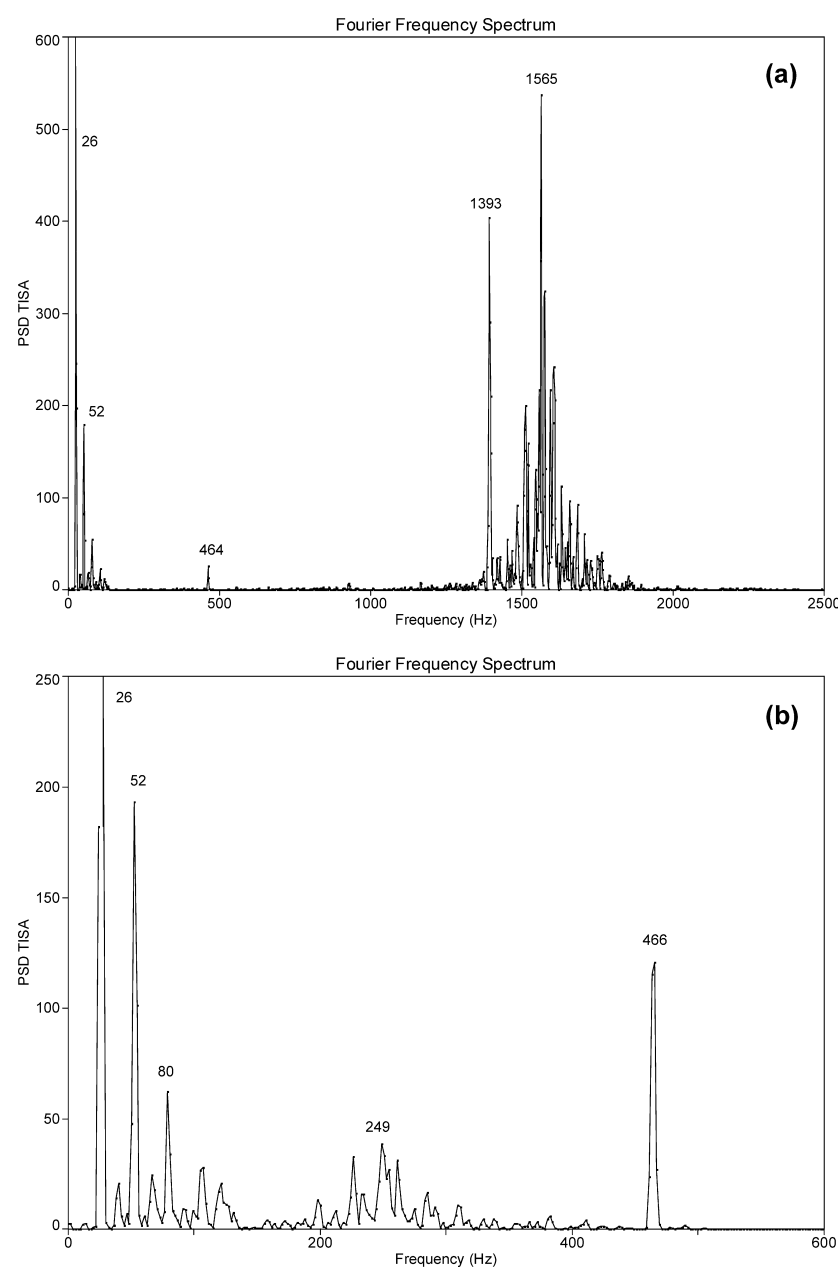

Fig. 11 Gear response FFT spectra for bearing clearance: (a) $10 \mu \mathrm{m}$ and (b) $60 \mu \mathrm{m}$ of dissipation power than with higher clearance (Fig. 11(b)). Although engine orders still dominate the spectrum, a band of frequencies initially centred on $1565 \mathrm{~Hz}$, when the bearing clearance is $10 \mu \mathrm{m}$ (Fig. 11(a)) moves to $249 \mathrm{~Hz}$ (Fig. 11(b)) as the bearing clearance is increased. Furthermore, the gear meshing frequency third order $(1393 \mathrm{~Hz})$ has a strong presence when bearing clearance is low, whereas the first order gets stronger with an increased clearance. A similar trend is observed at the higher temperatures of $80^{\circ} \mathrm{C}$, where the system response crosses the rattle threshold. This confirms that the clearance between the gear and the shaft can be effective in constraining the system from crossing the rattle threshold even when the temperature is relatively high.

The above case studies show that rattling occurs as a band of frequencies, which shift towards the lower spectral contributions as the drag, resisting the wheel motion decreases either due to an increase in the lubricant temperature or with an increase in the gear-shaft conjunctional clearance.

\subsection{The complete transmission model}

Figure 12 shows the fast Fourier transform (FFT) spectra of the second and fourth loose gears at the bulk oil temperature of $39.4^{\circ} \mathrm{C}$ with an assumed $10 \mu \mathrm{m}$ clearance in the gears-shafts conjunctions. The overall response of an idling gear consists of two particular motions: a carrier-type motion and superimposed infinitesimal fluctuations, containing different frequency characteristics (the former modulates the latter). The lower engine order responses dominate in the carrier region, whereas the higher vibro-impact frequencies are expected to govern the lower amplitude fluctuations [21].

The second idling gear pair (Fig. 12(a)), possessing a higher inertia, exhibits lower spectral components when compared with the fouth pair. The frequencies 292 and $505 \mathrm{~Hz}$ are the meshing frequencies of the second and fourth gear pairs, respectively (Table 1). On the other hand, the frequencies 198 and $266 \mathrm{~Hz}$ are the natural frequencies (those due to the balance of lubricated conjunctional characteristics) of the second and fourth gear pairs. The additional frequencies observed in the spectra $(218,248$, and $285 \mathrm{~Hz})$ are natural frequencies of the other gear pairs that are transmitted via the shafts and also excite the fourth idling gear.

Two simulated cases are compared with experimental measurements taken from a vehicle equipped with the same transmission type. The engine idling speed is $800 \mathrm{r} / \mathrm{min}$. Typical values for gear backlash are in the range $80-150 \mu \mathrm{m}$, with the larger value corresponding to the higher inertial gear pairs. The first comparison is made for the bulk oil temperature of $39.4{ }^{\circ} \mathrm{C}$ with the lubricant dynamic viscosity being $0.0512 \mathrm{~Pa}$ s. 

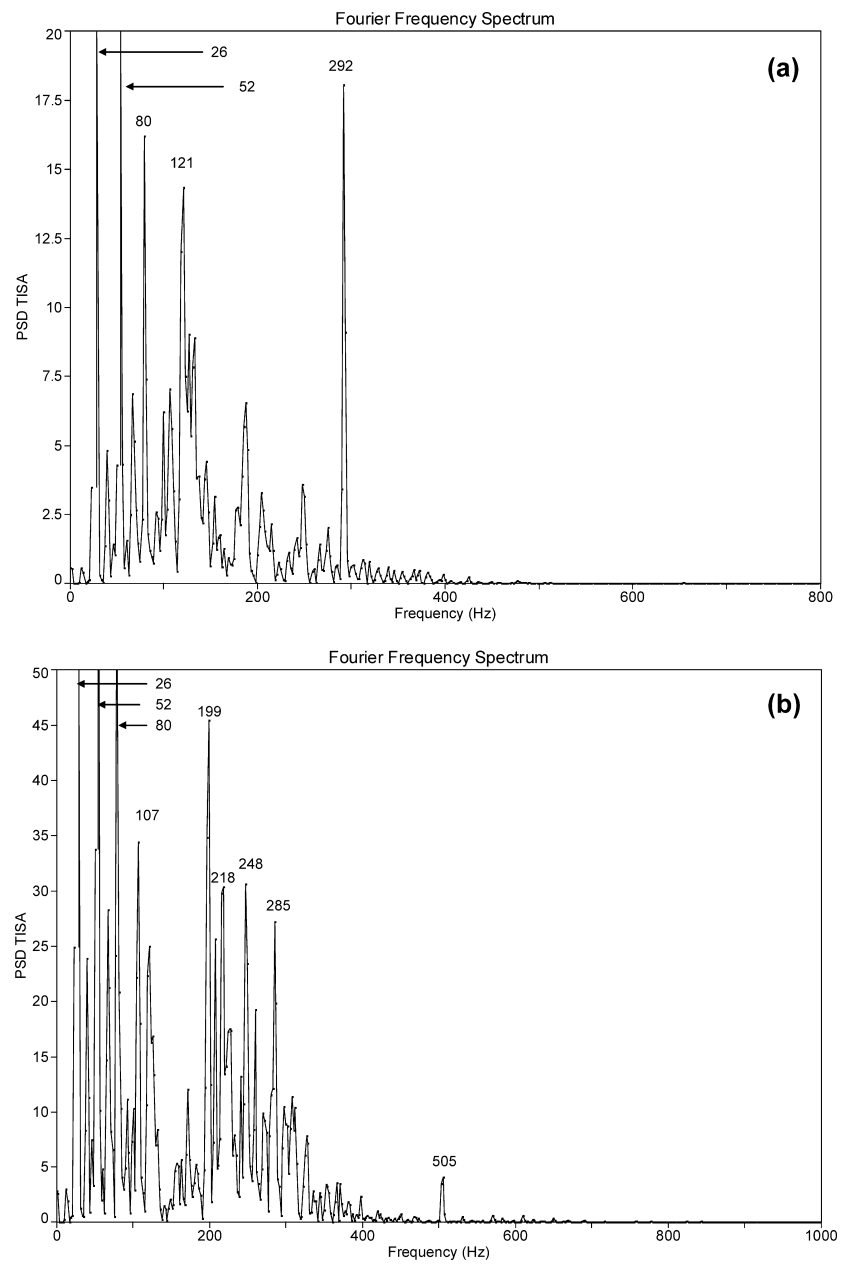

Fig. 12 Simulated response FFT spectra of (a) second and (b) fourth idle gear wheels

The responses of the housing captured by the accelerometers mounted on its wall and at the input shaft bearing position (Figs 13(a) and (b), respectively) contain contributions at 240 and $238 \mathrm{~Hz}$, respectively. These contributions correspond to the fourth wheel acceleration response (Fig. 12(b)) with an error of 4 per cent. The contribution at $350 \mathrm{~Hz}$ is the second harmonic of the first-gear meshing frequency, whereas the lower frequencies, 26,52 , and $80 \mathrm{~Hz}$, are engine order multiples. Additionally, the first gear's natural frequency is at $208 \mathrm{~Hz}$, which was obtained by solving the eigenvalue problem in reference [21]. This is also visible in the spectra of Figs 13(a) and (b). The frequency component at $286 \mathrm{~Hz}$ for the fourth loose gear response in Fig. 12(b) is within a margin of error of 5 per cent from the $273 \mathrm{~Hz}$ component captured
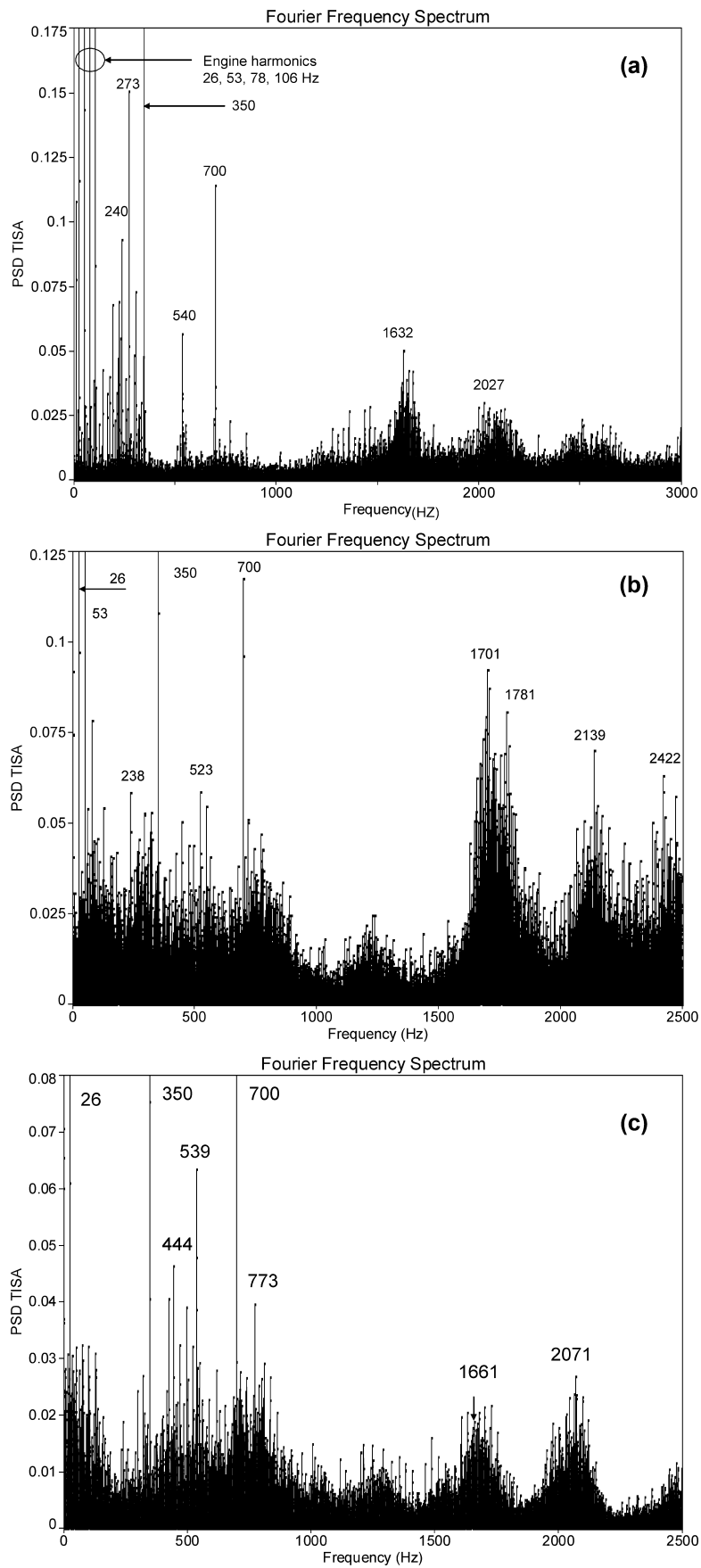

Fig. 13 FFT spectra of the (a) transmission wall response, (b) input bearing housing response, and (c) upper output bearing housing response (first case)

by the transmission wall accelerometer in Fig. 13(a). The contributions around $540 \mathrm{~Hz}$ in Fig. 13 represent approximately the second harmonic of $273 \mathrm{~Hz}$. The

Table 1 Meshing frequencies of the idle gear pairs at $800 \mathrm{r} / \mathrm{min}$ engine speed

\begin{tabular}{llllllll}
\hline Gear set & First & Second & Third & Fourth & Fifth & Sixth & Reverse \\
\hline Meshing frequency $(\mathrm{Hz})$ & 173.33 & 293.33 & 386.67 & 506.67 & 466.67 & 506.67 & 108.33 \\
\hline
\end{tabular}


meshing frequencies of the fourth, fifth, and sixth gear pairs are also present in Fig. 13 (in the regions of 466 and $506 \mathrm{~Hz}$ ). The frequencies above $1000 \mathrm{~Hz}$ in the same figure correspond to the natural frequencies of the output/input shafts and the gearbox casing [20].
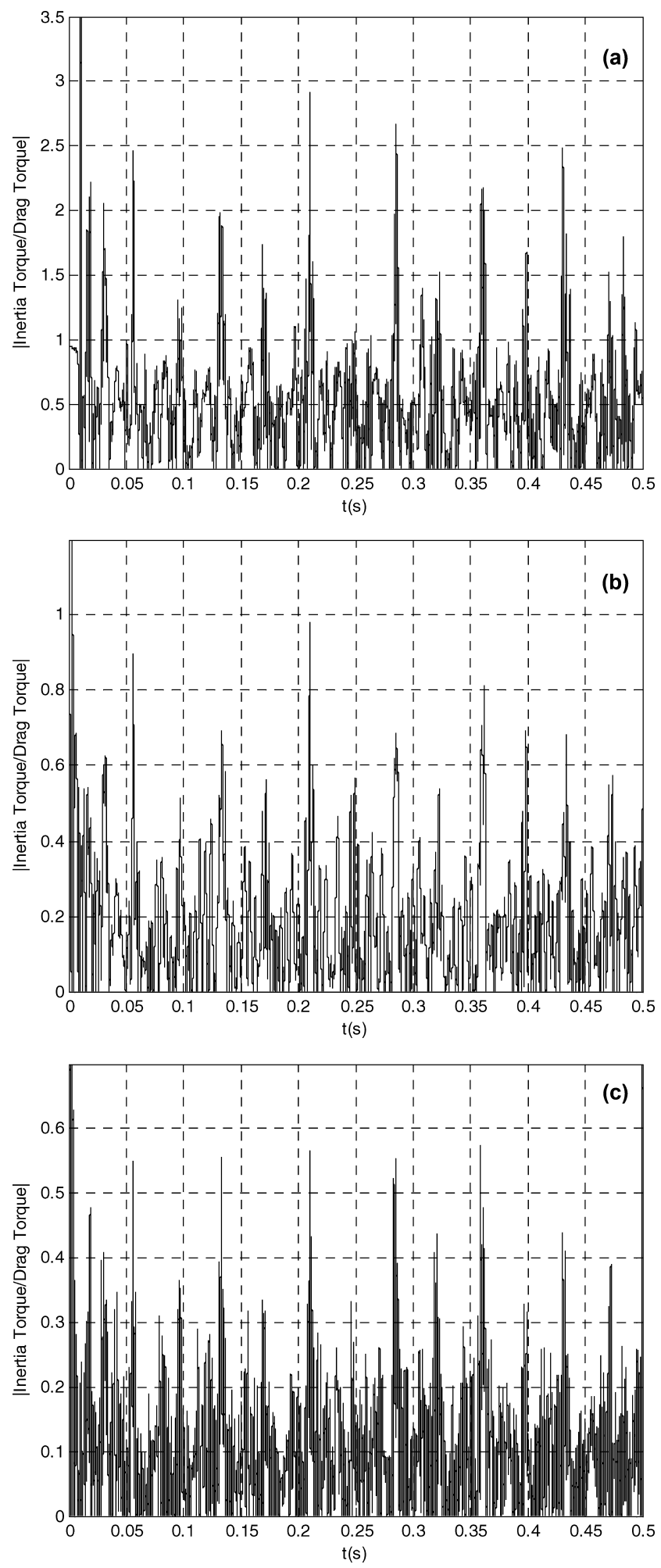

Fig. 14 Simulated rattle ratios of (a) first, (b) fourth, and (c) sixth gear wheels
Figures 14 and 15 show the rattle and squeezeto-rolling ratios of the first, fourth, and sixth gear pairs, respectively. Only the first gear crosses the rattle threshold, mainly due to the higher inertia of its loose wheel. The lubricant film reaction due to rolling action
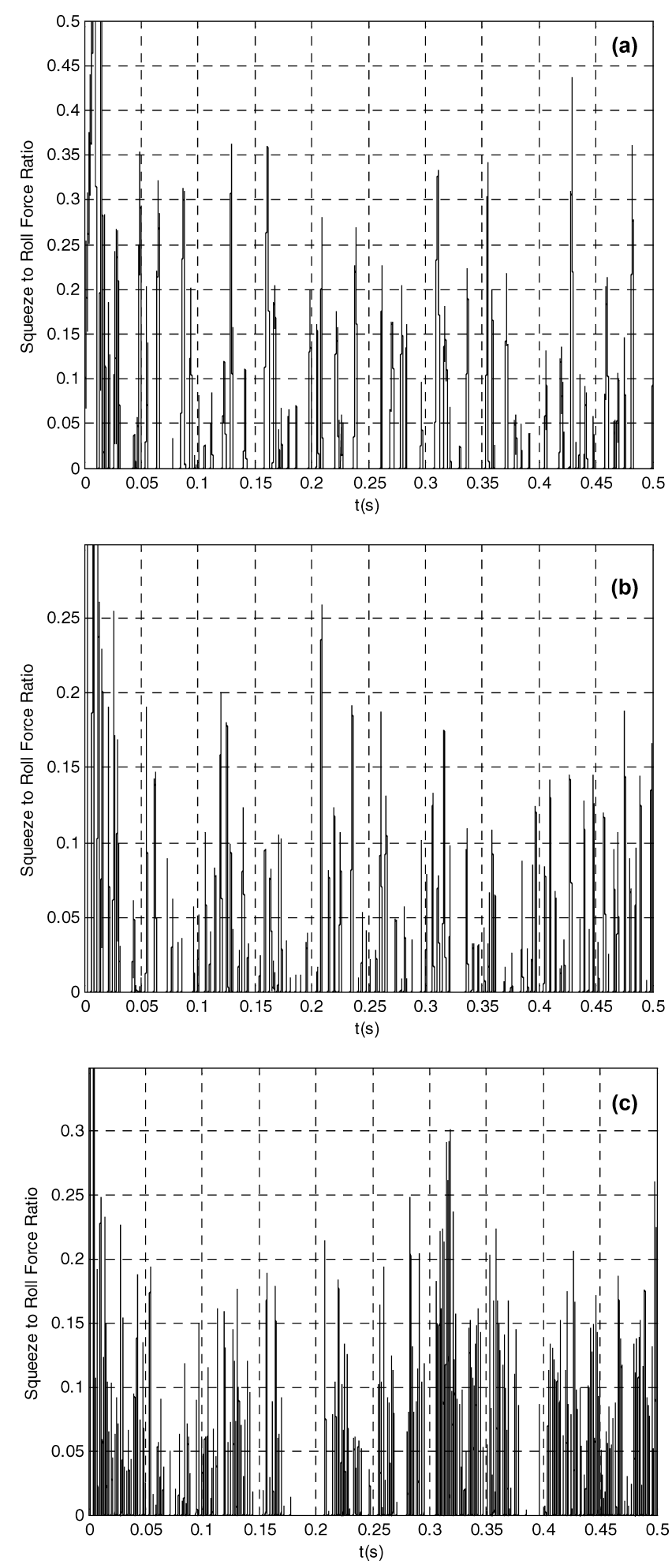

Fig. 15 Simulated squeeze-to-rolling ratios of (a) first, (b) fourth, and (c) sixth gear wheels 
is clearly dominant in all the three gears, as their corresponding squeeze-to-rolling force ratios are less than unity. The squeeze-to-rolling ratio assesses the contribution of squeeze action (approach leading to impact) to the system dynamics and it is obtained by dividing the squeeze term (second term) by the rolling term (first term) in equation (2)

$$
\begin{aligned}
& \text { Squeeze-to-roll force ratio } \\
& =\frac{3 \pi}{2 \sqrt{2}} \frac{|\partial h / \partial t|}{u_{\mathrm{ent}} \sqrt{h / r_{\mathrm{eq}}}}, \\
& \left.\begin{array}{ll}
\text { if } & \frac{\partial h}{\partial t}<0 \\
\text { if } \quad \frac{\partial h}{\partial t} \geqslant 0
\end{array}\right\}
\end{aligned}
$$

Equation (16) indicates that a combination of lowsqueeze action, as well as equivalent radius of curvature with high entraining velocity and larger film thickness would attenuate rattle. Thus, for design purposes, optimizing gear geometry in such a manner can be beneficial in terms of noise, vibration, and harshness $(\mathrm{NVH})$ behaviour.
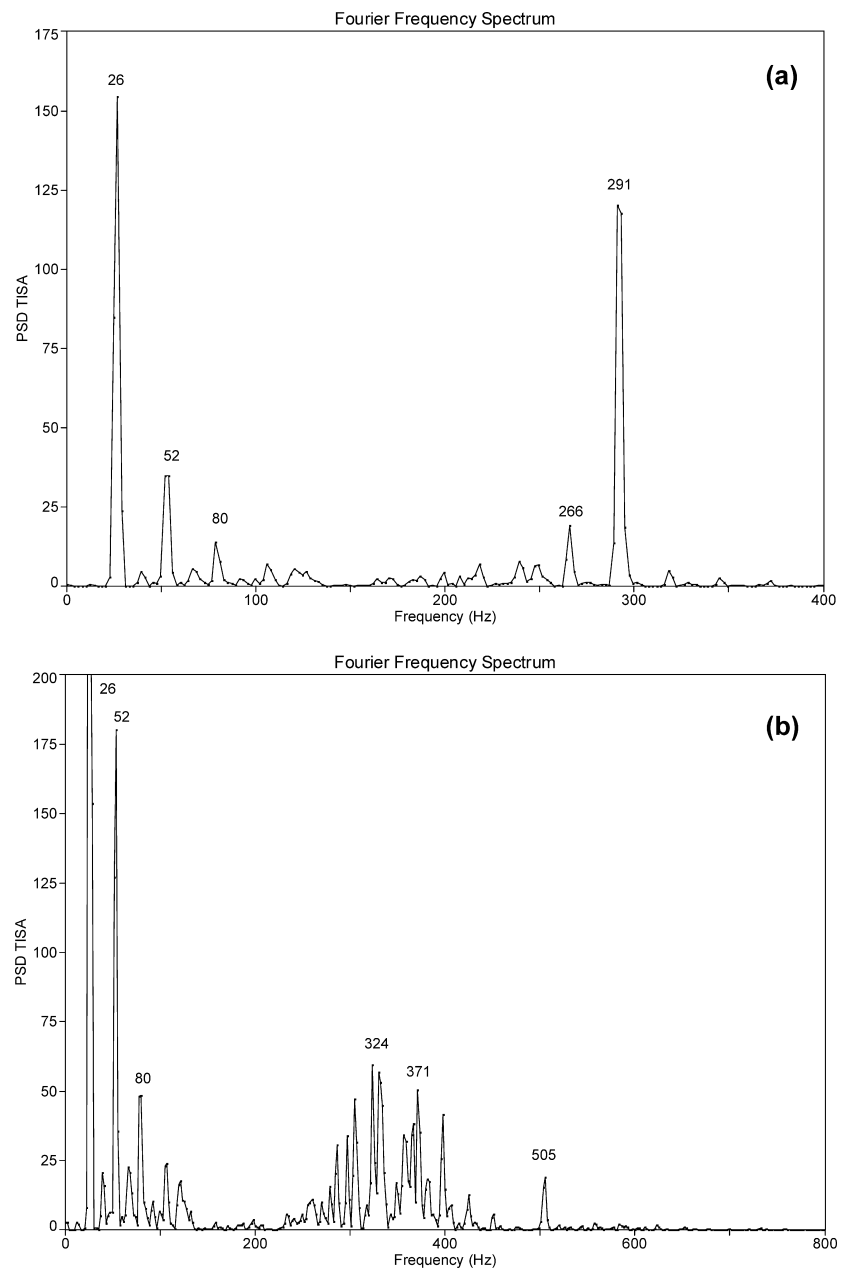

Fig. 16 Simulated response FFT spectra of (a) second and (b) fourth idle gear wheels
In the second predictions-measurements comparison case, the transmission lubricant temperature is $24.2{ }^{\circ} \mathrm{C}$, corresponding to a dynamic viscosity of $0.0951 \mathrm{Pas}$ (a stiffer spring/damper lubricant element). In Fig. 16(a), the acceleration response of the
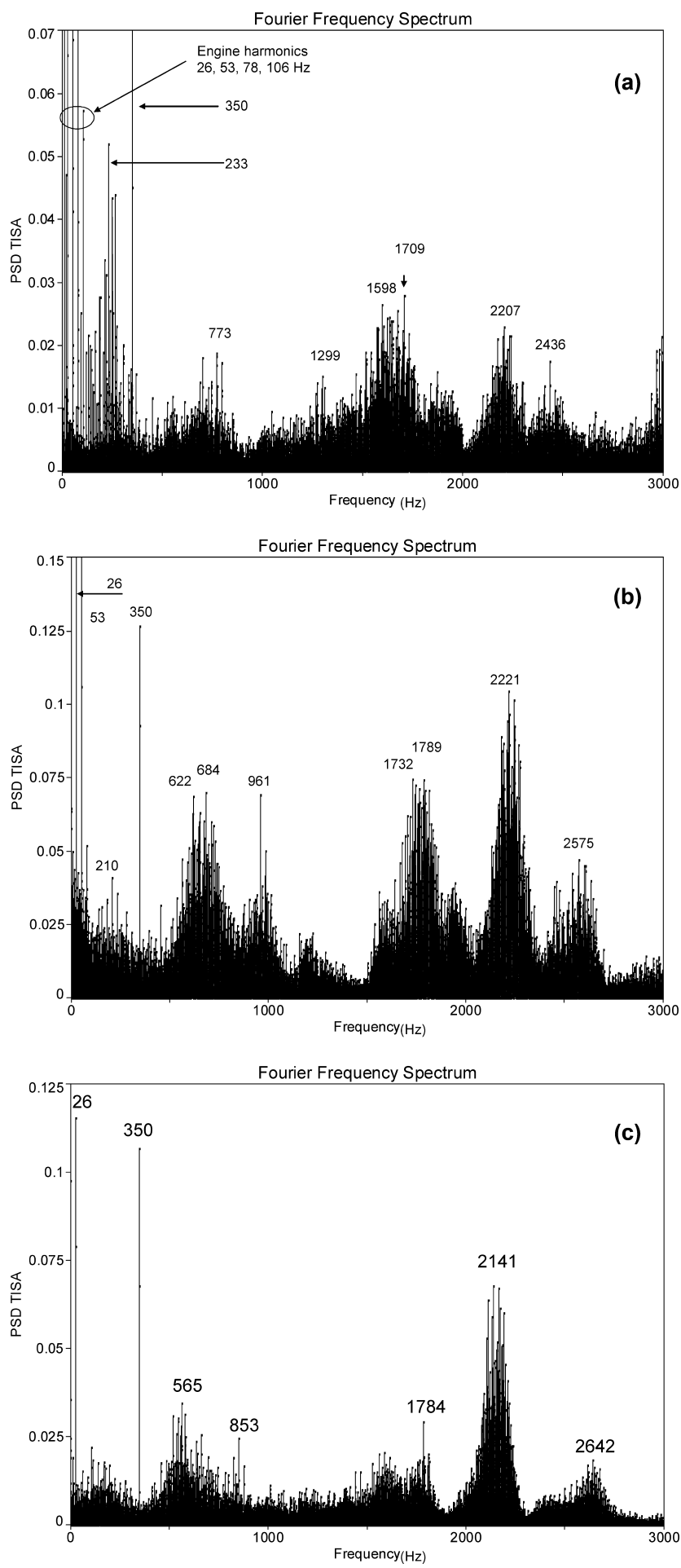

Fig. 17 FFT spectra of the (a) transmission wall response, (b) input bearing housing response, and (c) upper output bearing housing response (second case) 
second gear is dominated by its lubricant reaction contribution due to rolling action (engine orders and meshing frequency at $291 \mathrm{~Hz}$ ), whereas the squeeze action has a weaker presence at $266 \mathrm{~Hz}$, compared with that of Fig. 12(a) (corresponding to a higher temperature). A similar trend can be seen when comparing Figs 16(b) and 12(b). In Fig. 16(b), the natural frequency of the fourth gear pair (in the region of $352 \mathrm{~Hz}$ ) has a stronger presence than its meshing frequency $(505 \mathrm{~Hz})$.

The lower contributions in Fig. 17 (26, 52, and $80 \mathrm{~Hz}$ ) are engine order harmonics. The natural frequencies of the first and second gear pairs $(258$ and $256 \mathrm{~Hz}$, respectively) are close to the spectral contribution at $233 \mathrm{~Hz}$, which appears in the transmission wall spectrum (Fig. 17(a)). The $350 \mathrm{~Hz}$ contribution in the same figure is close to the natural frequency of the fourth gear pair, whereas that at $565 \mathrm{~Hz}$ corresponds to the sixth gear pair natural frequency. The $684 \mathrm{~Hz}$ contribution is associated with the fourth order of the first gear
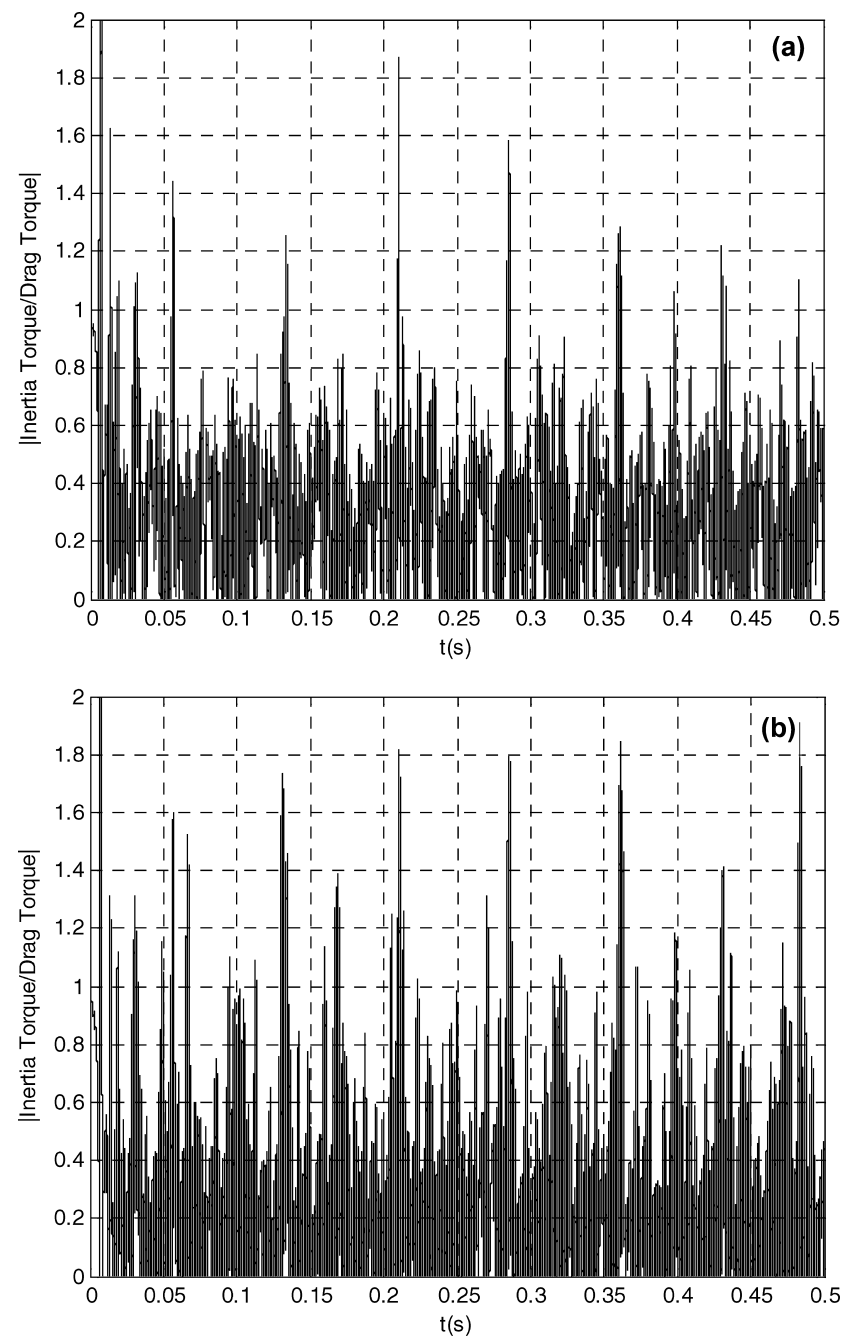

Fig. 18 Simulated rattle ratios of (a) first and (b) reverse gear wheels
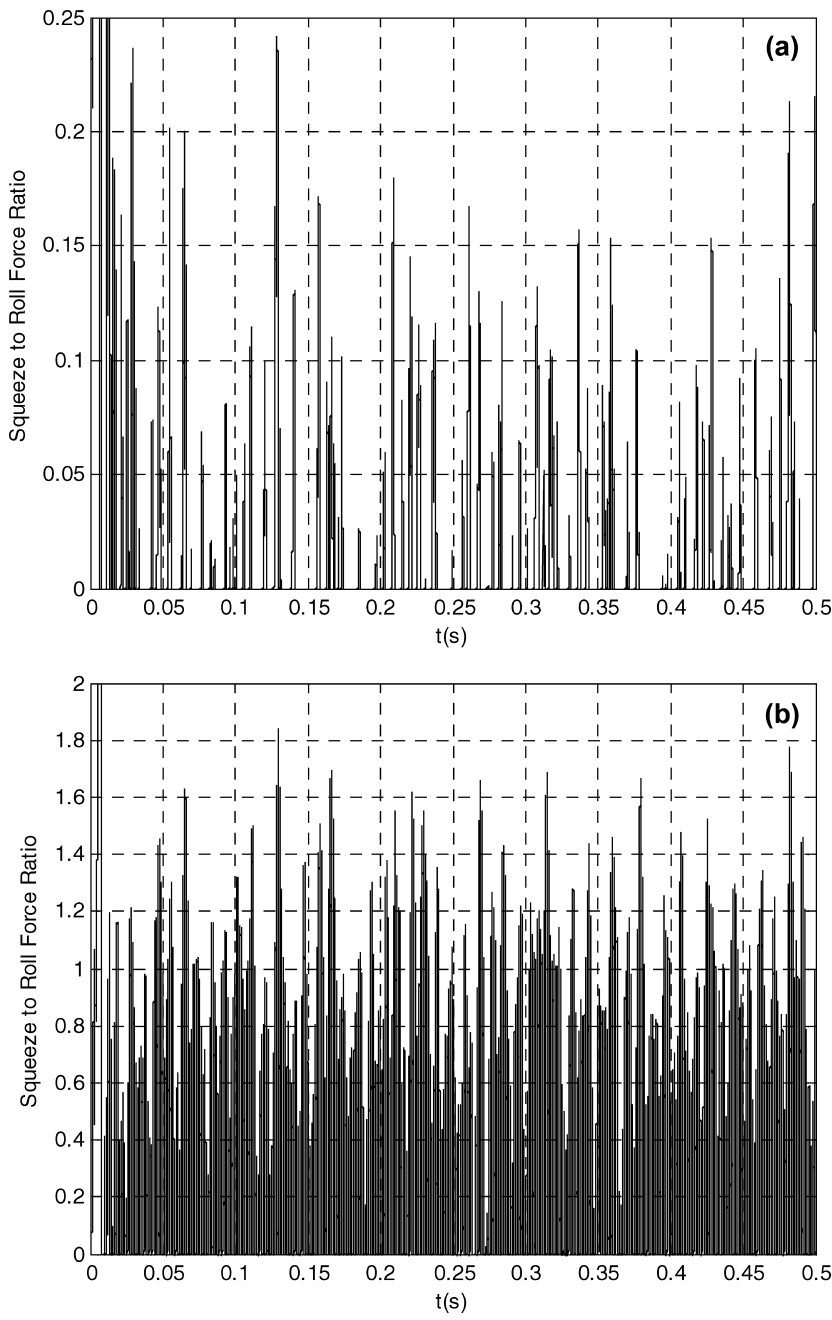

Fig. 19 Simulated squeeze-to-rolling ratios of (a) first and (b) reverse gear wheels

meshing frequency and modulations due to the engine order excitations. Again, the frequency components above $1000 \mathrm{~Hz}$ are associated with the shafts' natural frequencies and with the frequencies of the bell housing [20]. When inspecting the rattle ratios (Fig. 18), the responses of the first and reverse gears cross the rattle ratio threshold of unity. However, the squeezeto-rolling ratio (Fig. 19) reveals that only the reverse gear has a squeeze-to-roll force ratio that also crosses unity. This suggests that rattle condition is more severe in the case of reverse gear than for the first gear pair.

\section{CONCLUSIONS}

Idle rattle conditions have been studied using a gear pair and full transmission lumped parameter models. Comparisons with experimental measurements taken from a vehicle under similar conditions show good agreement. Most of the observed frequencies correspond to model predictions. It is concluded that 
gear rattle manifests itself as a band of frequencies, which shift towards lower spectral regions as the lubricant temperature rises. This band includes frequencies induced by the rolling and squeezing motions of lightly loaded hydrodynamic films. The effect of these contributions becomes clear by the squeeze-roll ratio, such that an emphatic squeeze action accompanies rattle behaviour. The gear design parameters determine the contact radii of curvature and lubricant entraining motion, which can be carefully selected in order to favourably influence the severity of rattle.

\section{ACKNOWLEDGEMENTS}

The authors gratefully acknowledge the financial support extended to this investigation by the Engineering and Physical Sciences Research Council (EPSRC) and Ford Motor Company. Technical support of Getrag Ford (GFT) is also acknowledged.

\section{REFERENCES}

1 Rust, A., Brandl, F. K., and Thien, G. E. Investigations into gear rattle phenomena - key parameters and their influence on gearbox noise. IMechE, C404/001, 1990, pp. 113-120.

2 Wang, M., Manoj, R., and Zhao, W. Gear rattle modelling and analysis for automotive manual transmissions. Proc. Instn Mech. Engrs, Part D: J. Automobile Engineering, 2001, 215(D2), 241-258.

3 Kim, T. and Singh, R. Dynamic interactions between loaded and unloaded gear pairs under rattle conditions. SAE technical paper 2001-01-1553, 2001, pp. 1934-1943.

4 Comparin, R. and Singh, R. An analytical study of automotive neutral gear rattle. J. Mech. Des., 1990, 112, 237-245.

5 Sakai, T., Doi, Y., Yamamoto, K., Ogasawara, T., and Narita, M. Theoretical and experimental analysis of rattling noise of automotive gearbox. SAE technical paper 810773, 1981, pp. 1-10.

6 Singh, R., Xie, H., and Comparin, R. Analysis of automotive neutral gear rattle. J. Sound Vibr., 1989, 131(2), 177-196.

7 Couderc, P. H., Callenaere, J., Der Hagopian, J., and Ferraris, G. Vehicle driveline dynamic behaviour: experimentation and simulation. J. Sound Vibr., 1998, 218(1), 133-157.

8 Bellomo, P., Cricenti, F., de Vito, N., Lang, C., and Minervini, D. Innovative vehicle powertrain systems engineering: beating the noisy offenders in vehicle transmissions. SAE technical paper 2000-01-0033, 2000.

9 Yakoub, R., Corrado, M., Forcelli, A., Pappalardo, T., and Dutre, $\mathbf{S}$. Prediction of system-level gear rattle using multibody and vibro-acoustic techniques. SAE technical paper 2004-32-0063/20044350, 2004.

10 Brancati, R., Rocca, E., and Russo, R. A gear rattle model accounting for oil squeeze between the meshing gear teeth. Proc. IMechE, Part D: J. Automobile Engineering, 2005, 219, 1075-1083.
11 Seaman, R., Johnson, C., and Hamilton, R. Component inertial effects on transmission design. SAE 841686, 1984, pp. 6.990-6.1008.

12 Ohnuma, S., Yahata, S., Inagawa, M., and Fujimoto, T. Research on idling rattle of manual transmission. SAE technical paper 850979, 1985.

13 Gnanakumarr, M., Theodossiades, S., and Rahnejat, $H$. The tribo-contact dynamics phenomenon in torsional impact of loose gears promoting gear rattle. In Society of Automotive Engineers (SAE)-ATT Congress, Paris, SAE 02ATT-138, 2002.

14 Smith, J. D. Gear noise and vibration, 1999 (Marcel Dekker, Inc., New York).

15 Doğan, S. N. Zur Minimierung der Losteilgeräusche von Fahrzeuggetrieben. PhD Thesis, Berichte Nr. 91, Institut für Maschinenelemente, Universität Stuttgart, 2001.

16 Fujimoto, T., Chikatani, Y., and Kojima, J. Reduction of idling rattle in manual transmission. SAE technical paper 870395, 1987, pp. 2.99-2.109.

17 Fujimoto, T. and Kizuka, T. An improvement of the prediction method of the idling rattle in manual transmission - in the case of the manual transmission with backlash eliminator. SAE technical paper 2001-01-1164, 2001.

18 Rahnejat, H. Computational modelling of problems in contact dynamics, engineering analysis. Comput. Mech., 1985, 2(4), 192-197.

19 Gohar, R. Elastohydrodynamics, 2nd edition, 2001 (Imperial College Press, London).

20 Tangasawi, O., Theodossiades, S., and Rahnejat, $\mathbf{H}$. Lightly loaded lubricated impacts: idle gear rattle. J. Sound Vibr., 2007, 308, 418-430.

21 Theodossiades, S., Tangasawi, O., and Rahnejat, H. Gear teeth impacts in hydrodynamic conjunctions promoting idle gear rattle. J. Sound Vibr., 2007, 303, 632-658.

22 Harris, T. A. Rolling bearing analysis, 4th edition, 2001 (John Wiley \& Sons, New York, USA).

23 Timoshenko, S., Young, D. H., and Weaver Jr., W. Vibration problems in engineering, 4th edition, 1974 (John Wiley \& Sons, New York).

24 Reese, S. Numerical methods in dynamics, Lecture notes (in English), Numerische Mechanik und Simulationstechnik, 2003 (Bochum Ruhr-Universität, Bochum).

\section{APPENDIX}

\section{Notation}

C

$C_{\mathrm{b}} \quad$ normal backlash (m)

$d_{k} \quad$ shafts' lateral displacement at bearing $k(k=\mathrm{a}, \mathrm{b}, \mathrm{c}, \mathrm{d}) ; d_{k}=x_{1 \mathrm{a}}, y_{1 \mathrm{a}}, x_{1 \mathrm{~b}}, y_{1 \mathrm{~b}}, x_{2 \mathrm{c}}$, $y_{2 \mathrm{c}}, x_{2 \mathrm{~d}}, y_{2 \mathrm{~d}}(\mathrm{~m})$

$f_{\mathrm{m}} \quad$ gear meshing frequency $(\mathrm{Hz})$

$F_{\mathrm{f}} \quad$ the viscous flank friction acting on the loose gear wheel $(\mathrm{N})$

$F_{\mathrm{f} i} \quad$ the viscous flank friction acting on the $i$ th loose gear wheel $(\mathrm{N})$ 


\begin{tabular}{|c|c|c|c|}
\hline \multirow{4}{*}{$\begin{array}{l}F_{\mathrm{p}} \\
F_{\mathrm{p} i}\end{array}$} & \multirow{2}{*}{$\begin{array}{l}\text { Petrov's hydrodynamic tractive force } \\
\text { (N) }\end{array}$} & $r_{\mathrm{bw}}$ & base radius of the gear wheel (m) \\
\hline & & $r_{\mathrm{b} i}$ & base radius of the $i$ th $(i=1,2, \ldots, 7)$ \\
\hline & Petrov's hydrodynamic tractive force & & loose gear wheel (m) \\
\hline & acting on the $i$ th $(i=1,2, \ldots, 7)$ loose & $r_{\mathrm{bp} 7}$ & base radius of the reverse pinion (m) \\
\hline & gear wheel $(\mathrm{N})$ & $r_{\mathrm{eq} j}$ & the reduced (equivalent) curvature \\
\hline$F_{r}$ & here, $r=x_{1}, y_{1}, x_{2}, y_{2}$, see below & & radius of the $j$ th meshing teeth pair in \\
\hline$F_{x 1}$ & the resultant force acting on the first & & normal plane (m) \\
\hline & $\begin{array}{l}\text { shaft in the } x \text {-direction due to the radial } \\
\text { and transverse components of the }\end{array}$ & $r_{\mathrm{s}}$ & $\begin{array}{l}\text { internal radius of the loose gear wheel } \\
\text { (m) }\end{array}$ \\
\hline \multirow{3}{*}{$F_{x 2}$} & hydrodynamic film reaction $(\mathrm{N})$ & $r_{\mathrm{si}}$ & internal radius of the $i$ th loose gear \\
\hline & the resultant force acting on the second & & wheel (m) \\
\hline & $\begin{array}{l}\text { shaft in the } x \text {-direction due to the radial } \\
\text { and transverse components of the }\end{array}$ & $u_{j}$ & $\begin{array}{l}\text { lubricant entraining velocity associated } \\
\text { with the } j \text { th teeth pair }(\mathrm{m} / \mathrm{s})\end{array}$ \\
\hline \multirow{3}{*}{$F_{y 1}$} & hydrodynamic film reaction $(\mathrm{N})$ & $u_{j \mathrm{~s}}$ & sliding velocity associated with the $j$ th \\
\hline & the resultant force acting on the first & & teeth pair $(\mathrm{m} / \mathrm{s})$ \\
\hline & $\begin{array}{l}\text { shaft in the } y \text {-direction due to the radial } \\
\text { and transverse components of the } \\
\text { hydrodynamic film reaction }(\mathrm{N})\end{array}$ & $v$ & $\begin{array}{l}\text { lubricant entraining velocity in the } \\
\text { conformal contact between gear and } \\
\text { the retaining shaft }(\mathrm{m} / \mathrm{s})\end{array}$ \\
\hline \multirow[t]{2}{*}{$F_{y 2}$} & the resultant force acting on the second & $W$ & the hydrodynamic reaction force $(\mathrm{N})$ \\
\hline & $\begin{array}{l}\text { shaft in the } y \text {-direction due to the radial } \\
\text { and transverse components of the } \\
\text { hydrodynamic film reaction }(\mathrm{N})\end{array}$ & $W_{i}$ & $\begin{array}{l}\text { the hydrodynamic reaction force acting } \\
\text { on the } i \text { th }(i=1,2, \ldots, 7) \text { loose gear } \\
\text { wheel (N) }\end{array}$ \\
\hline$h$ & $\begin{array}{l}\text { lubricant film thickness between the } \\
\text { gear pair teeth surfaces (m) }\end{array}$ & $W_{i \mathrm{t}}$ & $\begin{array}{l}\text { transverse component of } \\
\text { hydrodynamic reaction force acting on }\end{array}$ \\
\hline \multirow{2}{*}{$\frac{\partial h}{\partial t}$} & & & the $i$ th loose gear wheel $(\mathrm{N})$ \\
\hline & ueeze $1 \mathrm{~mm}$ verocity (m/s) & $W_{j}$ & hydrodynamic reaction force acting on \\
\hline \multirow{2}{*}{$i_{\text {time }}$} & time counter & & the $j$ th tooth in contact taken in the \\
\hline & $\begin{array}{l}\text { mass moment of inertia of the } i \text { th gear } \\
\text { wheel }\left(\mathrm{kg} \mathrm{m}^{2}\right)\end{array}$ & $x_{1}$ & $\begin{array}{l}\text { normal plane }(\mathrm{N}) \\
\text { first output shaft rigid body }\end{array}$ \\
\hline$I_{w}$ & $\begin{array}{l}\text { mass moment of inertia of the gear } \\
\text { wheel }\left(\mathrm{kg} \mathrm{m}^{2}\right)\end{array}$ & & $\begin{array}{l}\text { translational displacement in the } \\
\text { direction along the gear pair line of }\end{array}$ \\
\hline \multirow{2}{*}{$\begin{array}{l}j_{\text {iteration }} \\
K_{k}\end{array}$} & iteration counter & & centres (m) \\
\hline & $\begin{array}{l}\text { coefficient of (non-linear) stiffness of } \\
\text { bearing } k(k=\mathrm{a}, \mathrm{b}, \mathrm{c}, \mathrm{d})\left(\mathrm{N} / \mathrm{m}^{1.11}\right)\end{array}$ & $\ddot{x}_{1}$ & $\begin{array}{l}\text { first output shaft rigid body } \\
\text { translational acceleration in the }\end{array}$ \\
\hline \multirow[t]{2}{*}{$K_{k r}$} & $\begin{array}{l}\text { coefficient of (non-linear) stiffness of } \\
\text { bearing } k(k=\mathrm{a}, \mathrm{b}, \mathrm{c}, \mathrm{d}) \text { in the }\end{array}$ & & $\begin{array}{l}\text { direction along the gear pair line of } \\
\text { centres }\left(\mathrm{m} / \mathrm{s}^{2}\right)\end{array}$ \\
\hline & $r\left(r=x_{1}, y_{1}, x_{2}, y_{2}\right)$ direction $\left(\mathrm{N} / \mathrm{m}^{1.11}\right)$ & $x_{2}$ & second output shaft rigid body \\
\hline \multirow[t]{2}{*}{$l_{1}$} & $\begin{array}{l}\text { length of contact line in the conformal } \\
\text { contact of gear wheel and retaining }\end{array}$ & & $\begin{array}{l}\text { translational in the direction along the } \\
\text { gear pair line of centres }(\mathrm{m})\end{array}$ \\
\hline & shaft $(\mathrm{m})$ & $\ddot{x}_{2}$ & second output shaft rigid body \\
\hline$l_{k}$ & $\begin{array}{l}\text { length of roller bearings } k \\
(k=\mathrm{a}, \mathrm{b}, \mathrm{c}, \mathrm{d})(\mathrm{m})\end{array}$ & & $\begin{array}{l}\text { translational acceleration in the } \\
\text { direction along the gear pair line of }\end{array}$ \\
\hline \multirow[t]{2}{*}{$L_{j}$} & length of contact line on the meshing & & centres $\left(\mathrm{m} / \mathrm{s}^{2}\right)$ \\
\hline & teeth flank of the $j$ th teeth pair (m) & $x_{i k}$ & displacement of the $i$ th $(i=1,2)$ shaft \\
\hline$m_{k}$ & $\begin{array}{l}\text { the number of rollers in support } \\
\text { bearing } k(k=\mathrm{a}, \mathrm{b}, \mathrm{c}, \mathrm{d})\end{array}$ & & $\begin{array}{l}\text { at bearing } k(k=\mathrm{a}, \mathrm{b}, \mathrm{c}, \mathrm{d}) \text { along the } \\
x \text {-direction }(\mathrm{m})\end{array}$ \\
\hline$N$ & $\begin{array}{l}\text { total number of teeth in simultaneous } \\
\text { contact }\end{array}$ & $y_{1}$ & $\begin{array}{l}\text { first output shaft rigid body } \\
\text { translational displacement in the }\end{array}$ \\
\hline \multirow[t]{2}{*}{$N_{i}$} & $\begin{array}{l}\text { total number of teeth in simultaneous } \\
\text { contact of the } i \text { th }(i=1,2, \ldots, 7) \text { gear }\end{array}$ & & $\begin{array}{l}\text { direction normal to the gear pair line of } \\
\text { centres }(\mathrm{m})\end{array}$ \\
\hline & wheel & $\ddot{y}_{1}$ & first output shaft rigid body \\
\hline \multirow[t]{2}{*}{$Q_{k r}$} & $\begin{array}{l}\text { the reduced non-linear coefficient of } \\
\text { the inner and outer raceways' contact } \\
\text { with the bearing } k(k=\mathrm{a}, \mathrm{b}, \mathrm{c}, \mathrm{d}) \text { roller }\end{array}$ & & $\begin{array}{l}\text { translational acceleration in the } \\
\text { direction normal to the gear pair line of } \\
\text { centres }\left(\mathrm{m} / \mathrm{s}^{2}\right)\end{array}$ \\
\hline & $\begin{array}{l}\text { associated with the bearing reaction in } \\
r\left(r=x_{1}, y_{1}, x_{2}, y_{2}\right) \text { direction }\end{array}$ & $y_{2}$ & $\begin{array}{l}\text { second output shaft rigid body } \\
\text { translational displacement in the }\end{array}$ \\
\hline
\end{tabular}


$\ddot{y}_{2}$

$y_{i k}$

$\alpha_{\mathrm{n}} \quad$ normal pressure angle (rad)

$\beta \quad$ helix angle (at pitch circle (rad)

$\beta_{\mathrm{b}} \quad$ helix angle (at base circle) (rad)

$\beta_{\mathrm{b} i} \quad$ helix angle (at base circle) the

$\gamma_{k}$

$\delta_{k r}$

$\Delta_{k}$

$\eta_{0}$

$\Lambda_{k r}$ direction normal the gear pair line of centres (m)

second output shaft rigid body

translational acceleration in the

direction normal to the gear pair line of centres $\left(\mathrm{m} / \mathrm{s}^{2}\right)$

displacement of the $i$ th $(i=1,2)$ shaft

at bearing $k(k=\mathrm{a}, \mathrm{b}, \mathrm{c}, \mathrm{d})$ along the

$y$-direction (m)

$i$ th $(i=1,2, \ldots, 7)$ loose gear wheel

(rad)

contact angle of support bearing

$k(k=\mathrm{a}, \mathrm{b}, \mathrm{c}, \mathrm{d})(\mathrm{rad})$

radial deformation of bearing

$k(k=\mathrm{a}, \mathrm{b}, \mathrm{c}, \mathrm{d})$ in the

$r\left(r=x_{1}, y_{1}, x_{2}, y_{2}\right)$ direction $(\mathrm{m})$

$(k=\mathrm{a}, \mathrm{b}, \mathrm{c}, \mathrm{d})$

lubricant dynamic viscosity (Pa s)

the restoring force of bearing

$k(k=\mathrm{a}, \mathrm{b}, \mathrm{c}, \mathrm{d})$ in the

$r\left(r=x_{1}, y_{1}, x_{2}, y_{2}\right)$ direction $(\mathrm{N})$

$\varphi_{\mathrm{w}}$

$\dot{\varphi}_{\mathrm{w}}$

$\ddot{\varphi}_{\mathrm{W}}$ convergence criterion (rad)

radius of curvature of the

$i$ th $(i=1,2, \ldots, 7)$ loose gear wheel

surface $(\mathrm{m})$

tooth surface radius of curvature (m)

acceleration of the $i$ th $(i=1,2, \ldots, 7)$

loose gear wheel $\left(\mathrm{rad} / \mathrm{s}^{2}\right)$

angular displacement of the input shaft (rad)

angular velocity of the input shaft $(\mathrm{rad} / \mathrm{s})$

angular acceleration of the input shaft $\left(\mathrm{rad} / \mathrm{s}^{2}\right)$

pinion's angular displacement (rad)

angular velocity of the pinion

( $\mathrm{rad} / \mathrm{s})$

angular acceleration of the pinion $\left(\mathrm{rad} / \mathrm{s}^{2}\right)$

initial angular displacement of the wheel (rad)

angular displacement of the wheel

(rad)

angular velocity of the wheel ( $\mathrm{rad} / \mathrm{s})$ angular acceleration of the wheel $\left(\mathrm{rad} / \mathrm{s}^{2}\right)$ 
